\title{
Reproductive compensation and embryo competition drive the evolution of polyembryony
}

November 17, 2020

\section{Institutional affiliations}

Yaniv Brandvain: Department of Plant and Microbial Biology, University of Minnesota, St. Paul, Minnesota 55108

Alexander Harkness: Department of Ecology, Evolution, and Behavior, University of Minnesota, St. Paul, Minnesota 55108

Tanja Pyhäjärvi: Department of Ecology and Genetics, University of Oulu, FI-90014 Oulu, Finland.

\section{Corresponding author contact details}

Corresponding author: Yaniv Brandvain. 1500 Gortner Ave. St. Paul, MN, USA 55108. ybrandva@umn.edu

\section{Keywords}

Self-Incompatibility

Polyembryony

Sibling Rivalry 


\begin{abstract}
Simple polyembryony - where a single gametophyte produces multiple embryos with different sires but the same maternal haplotype - is common in conifers, ferns, horsetails and other vascular plants. Polyembryony could be favored as a mechanism of reproductive compensation, providing a backup for inviable embryos, or as a mechanism of embryo competition and eliminating plants with low fitness, perhaps acting as a mechanism of SelfIncompatibility (SI). However as the evolution of polyembryony from monoembryony has not been modeled these long standing verbal models have not been evaluated. We develop an infinitesite, forward population genetics model to test how these factors can favor the evolution of polyembryony, and how these underlying benefits of polyembryony shape the genetic load under a range of selfing rates, dominance, and selection coefficients. We find that the benefit of reproductive compensation strongly favors the evolution of polyembryony, while the benefits of embryo competition are much weaker. Importantly, when embryo competition favors the evolution of polyembryony it increases embryo competitiveness, but does not act as an SI mechanism, as it does not effectively trade low-fitness selfed offspring for high fitness outcrossed offspring. We find that the impact of polyembryony on the genetic load depends on its function - increasing the embryo load when acting as a mechanism of embryo compensation and decreasing the embryo load when acting as a mechanism of competition.
\end{abstract}


47 ity) and compensation (akin to egret mothers hedging their bets) theories

48 for the evolution of polyembryony, and to investigate how polyembryony

Nature is, above all, profligate. Don't believe them when they

tell you how economical and thrifty nature is.

- Annie Dillard 1974.

Not only do most parents produce more offspring than will survive, but most organisms that provide parental care make more offspring than they will likely be able to nurture to independence. Frequent siblicide in the great egret, Casmerodius albus, provides a dramatic example of this - siblings kill one another, presumably over the ability to monopolize small food items (Mock 1984); Why then do egret mothers continue laying eggs that will develop into offspring that will kill one another? Could such overproduction allow parents to screen for offspring quality (Forbes and Mock 1998), or does the "diverse portfolio" of offspring born over the breeding season allow parents to hedge their bets (Forbes 2009)?

Simple polyembryony provides an even more extreme, but perhaps less dramatic, example of this problem. With simple polyembryony, a single maternal gametophyte is fertilized by multiple sperm cells to produce multiple embryos with genetically identical maternally derived genomes but distinct paternal genomes (Buchholz 1922, Schnarf 1937, cited in Dogra 1967). Here we present an infinite sites forward-in-time population genomic simulation to test the competition (akin to egret mothers screening for offspring qualchanges the genetic architecture of embryonic and postembryonic fitness.

Simple polyembryony is ubiquitous in gymnosperms (Willson and Bur1 ley 1983), and is found in many seedless vascular plants including ferns and horsetails (Buchholz 1922). The number of archegonia per seed typically 
varies from two to four in the genus Pinus, but can reach up to 200 (as reported in Widdringtonia juniperoides Saxton 1934). In gymnosperms, from

this base of numerous archegonia, typically only a single embryo survives in mature seed (Chamberlain 1966).

Evolutionary theorists have investigated the evolutionary consequences of polyembryony - specifically how polyembryony (or less mechanistically explicit forms of reproductive compensation) could shape the genetic load (Latta 1995; Sakai 2019; Porcher and Lande 2005, Kärkkäinen et al. 1996) and the exposure of inbreeding depression (Kärkkäinen and Savolainen 1993, Hedrick et al. 1999). However, theories for the evolutionary origin of simple polyembryony are less well developed. Here, we develop theory for the evolution of simple polyembryony. We do not consider cleavage polyembryony, in which a fertilized zygote can split into numerous genetically identical embryos (Agapito-Tenfen et al. 2012), or nucellar polyembryony, in which maternal tissue asexually develops into embryos (Lakshmanan and Ambegaokar 1984), sometimes competing with sexually derived embryos, as they are likely favored by distinct mechanisms (Ganeshaiah et al. 1991).

We consider the two major advantages of simple polyembryony described by Kärkkäinen and Savolainen (1993): reproductive compensation - improved seed set, and embryo competition - the potentially improved postembryonic fitness of surviving embryos compared to the projected fitness of unsuccessful embryos (Sorensen 1982; Porcher and Lande 2005). Reproductive compensation is an increase in seed set that occurs when embryo mortality is counteracted by an expanded supply of embryos. Polyembryony provides reproductive compensation if a lone embryo is less likely to develop into a successful seed than is a collection of sibling embryos. So, for example, if a proportion $p$ of embryos are inviable, a second embryo increases the 
probability that a seed contains a surviving embryo from $1-p$ to $1-p^{2}$ (Lindgren 1975).

Alternatively, if embryonic and post-embryonic fitness a positively correlated, embryo competition (dubbed Developmental Selection by Buchholz $(1922)$ ), could favor the evolution of polyembryony. Such a correlation can arise either through pleiotropy across the life cycle, or if embryonic fitness determined by one set of loci predicted post-embryonic fitness produced by another set of loci. This later option seems particularly likely if inbred offspring are unfit across the life cycle, and as such, simple polyembryony is often interpreted as an inbreeding avoidance mechanism (e.g. Dogra 1967 Sorensen 1982) analogous to the self-incompatibility systems (hereafter SI) found in angiosperms. Koski (1971) and others contend that this gives way to evolution of the so-called "Embryo Lethal System" - an apparently coordinated self destruction mechanism revealed upon inbreeding (Koski 1971; Sarvas 1962, e.g. page 162 onwards ) in pines - as a mechanism evolved to prevent selfing. Under this model, polyembryony does not prevent self-fertilization per se, but dampens self-fertilization's deleterious effects by allowing competition and something of a maternal choice among the selfed and outcrossed progeny before major maternal resource allocation (Willson and Burley 1983; Sorensen 1982). This potential form of postzygotic mate choice could circumvent the constraint imposed by the unenclosed gymnosperm seed, which precludes prezygotic mate choice (e.g. SI systems Dogra 1967; Sorensen 1982, Willson and Burley 1983).

Critically, the embryo competition model assumes that possibility of effective competition between embryos in a seed, a topic of much debate. Based on extensive experimental work on P. sylvestris, Sarvas (1962) stated that embryo competition and "struggle for life" is quite apparent under mi- 
croscopic observation. However, others argue that selfed embryo death primarily occurs after the dominant embryo is determined (Williams|2008), and embryo survival is determined by chance physical factors Williams (2007); Mikkola (1969), undercutting the embryo competition model. Empirical studies evaluating these ideas are quite rare, and the evidence from these studies is mixed. For example, O'Connell and Ritland (2005) conducted controlled pollinations with varying levels of self-pollen with Thuja plicata, and found that the effect of embryo competition became apparent with a probability of selfing (0.75), that exceeds reasonable estimates of the frequency of self-pollination in most conifers. However, subtle effects at lower selfing rates are plausible.

In addition to various selective forces favoring the evolution of polyembryony, polyembryony itself can have striking evolutionary consequences. Previous models (Porcher and Lande 2005; Klekowski 1982; Sorensen 1982) examined the effect of reproductive compensation on the number of deleterious mutations, mean population fitness, the extent of inbreeding depression, and the realized selfing rate. These models generally show that because removing selfed embryos early in development, polyembryony will prevent the effective purging of deleterious recessive mutations (Klekowski 1982; Haig 1992), will increases the number of deleterious mutations at equilibrium, increase the extent of inbreeding depression, and decrease the realized selfing rate while increasing population mean fitness. As such, polyembryony is often suggested as an explanation for the joint observation of high inbreeding depression (gymnosperms have an estimated 5-10 lethal equivalents per haploid genome Lynch and Walsh 1998; Williams and Savolainen 1996) and low realized selfing rates in gymnosperms (Kärkkäinen and Savolainen 1993 Hedrick et al. 1999). Likewise, polyembryony could explain the absence of 
a relationship between inbreeding depression and the primary selfing rate in gymnosperms (Husband and Schemske 1996). However other models of polyembryony make drastically different predictions — for example, Latta (1995) modelled the embryo competition component of polyembryony and found that e.g., under a mild mutations model, polyembryony decreased the number of deleterious mutations per individual. In this work we uncover that much of these differences are attributable to implicit modelling decisions that consider polyembryony as a mechanism of embryo choice or reproductive compensation.

The previous work described above provide some insight into the evolutionary consequences of polyembryony, but contains numerous modelling assumptions that limit their applicability to major questions in the evolution of polyembryony and its consequences. For example, comparing cases with and without reproductive compensation, Porcher and Lande (2005) showed that reproductive compensation can favor the evolution of selfing and can allow for the maintenance of mixed mating systems, while Sakai (2019) showed that selective embryo abortion could allow for the maintenance of high levels of inbreeding depression in selfing species. But if the mating system of an initially monoembryonic population affects whether polyembryony evolves in the first place, this initial condition may affect subsequent mating system evolution after the transition to polyembryony. A second limitation with current theory of the evolutionary consequences of polyembryony is that each model has focused on a single dominance and selection coefficient. As such, while current theory predicts evolution of the number and frequency of deleterious mutations, the magnitude of genetic load, it cannot predict evolution of the distributions of dominance or selection coefficients, the architecture of genetic load. This limitation has 
prevented theory from addressing Koski's 1971 hypothesis that the "Embryo

Lethal System" evolved as an altruistic mechanism by which inbred embryos sacrifice themselves to prevent their mothers from selfing, as opposed to the parsimonious alternative that selfing simply exposes the elevated number of deleterious mutations that can accumulate under polyembryony.

Here we present a series of infinite-sites forward population genetic simulations of polyembryony. This model allows us to evaluate the relative importance of competition and compensation to the evolution of polyembryony, the evolutionary consequences of alternative models of embryo selection, and if polyembryony can favor the evolution of an increased recessive load as a mechanism to prevent inbreeding.

\section{Methods}

\section{Overview}

We present a series of models to disentangle the contribution of the potential evolutionary benefits of compensation and competition to the evolution of polyembryony. To better understand how and when these factors favor the evolution of polyembryony, we vary the distribution of dominance and fitness effects and the probability of selfing. Importantly, by changing the underlying probability of selfing, we can address the possibility that when polyembryony evolves as a mechanism of embryo competition, that it may in fact be favored as a mechanism of preventing the generation of self-fertilized offspring. That is, we may hypothesize that polyembryony can evolve to minimize the realized selfing rate. When polyembryony does evolve, we ask how its evolution shapes the genetic load and its architecture.

The life cycle begins with $N=1000$ diploid seeds, each of which has 
one or two embryos, depending on whether mothers are mono- or polyembryonic. Following embryo selection, surviving seed parents for the next generation are chosen with replacement with a probability reflecting their post-embryonic fitness. Each time a seed parent is chosen, it generates one of the $\mathrm{N}$ seeds in the next generation, thus maintaining a constant population size. Each embryo in the seed is fertilized independently. If directly selfed, which occurs with probability equal to the selfing rate, the seed parent of an embryo is also its pollen parent, otherwise the pollen parent is selected at random and in proportion to adult fitness. Next, gametes are formed by free recombination and each gamete acquires mutations. Finally, fusion between gametes generates the seeds and embryos for the next generation $(? ?)$.

\section{Parameters and model details}

Genome structure and mutation rate: Every generation, each haploid genome expects a Poisson distributed number (mean $U$ ) of de novo deleterious mutations to arise, each at any one of an infinite number of unlinked sites (i.e. an infinite sites model). We investigate cases with $U=0.5$ mutations per haploid chromosome per generation.

The timing of mutational effects: We focus on the case in which half of de novo deleterious mutations impact embryonic fitness and the other half impact post-embryonic fitness. Our code also allows mutations to influence both pre- and post-embryonic fitness pleiotropically. However our initial early investigation showed that this pleiotropic effect trivially favored the evolution of polyembryony, so we do not investigate this pleiotropic model here. 


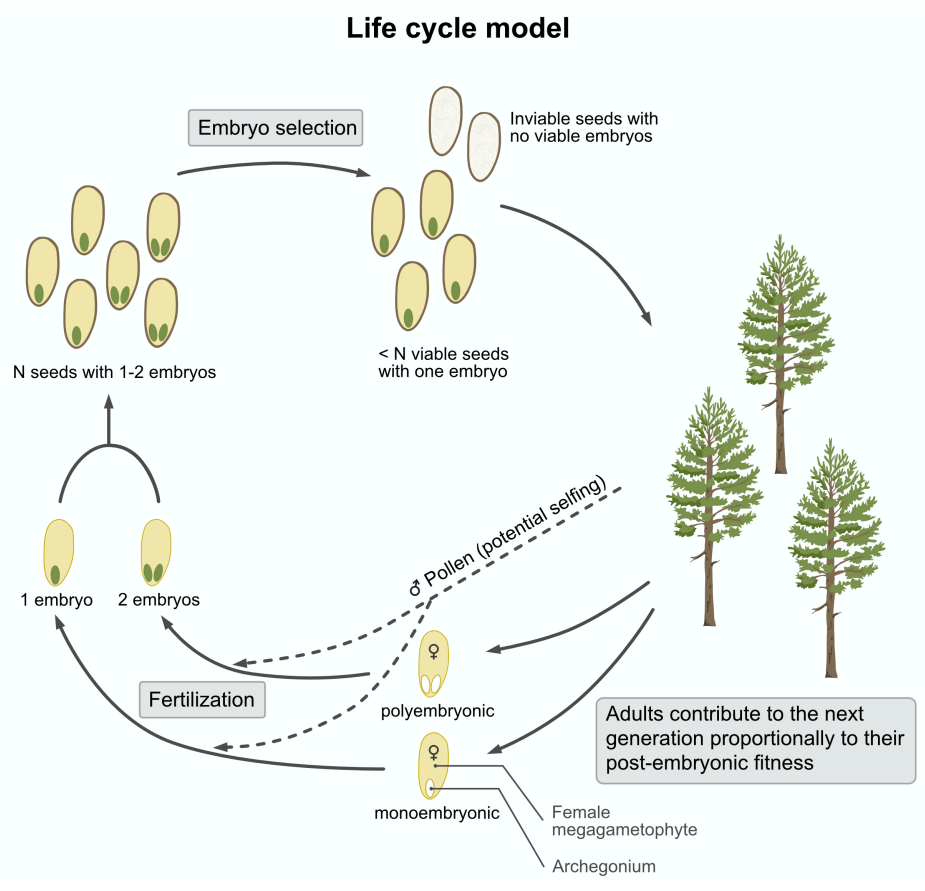

Figure 1: Overview of the life cycle model: The life cycle starts with $N$ seeds, each with one or two embryos, followed by embryo and seed selection. Because of seed inviabiliy, the number of plants will be less than $n$. Seed parents are chosen with replacement in proportion to their postembryonic fitness, and directly self with probability $p_{\text {self. Both embryos of }}$ polyembryonic mothers are fertilized independently, and pollen parents of non-selfed seed are sampled with from the population with replacement in proportion to each genotypes post-embryonic fitness. Seed parents carrying the dominant polyembryony allele, produce two archegonia per seed, while those without this allele produce only one.

The distribution of fitness and dominance effects of new mutations:

For all parameter values, fitness effects $(s)$ across loci are multiplicative and independent Bramlett and Bridgwater 1986, as cited in Williams and Savolainen 1996), such that the fitness of the $i^{\text {th }}$ individual, $w_{i}$, equals the

215 product of one minus the deleterious effect of their genotype at the $k^{\text {th }}$ 
of mutational architecture on the evolution of polyembryony, we compare models with a different value of fitness $(s)$, and dominance $(h)$ effects of new mutations. For s we present cases with $s=0.1, s=0.5, s=1$, and $s=$ Uniform $(20 / N, 1)$. Dominance, $h$, can take any value between 0 and 1 , but we present cases with full recessivity $(h=0)$ and full additivity $(h=0.5)$, as well as a case where the dominance of each mutation takes a random value between zero and one from the uniform distribution $(h=\operatorname{Uniform}(0,1))$. Thus, mutation effects span the range from quite deleterious to lethal, but will not reach fixation by random genetic drift. Practically, this means that we save considerable computational resources, and that we do not consider weakly deleterious mutations whose fixation is not effectively prevented by selection. In all simulations, we assumed that the distribution of fitness and dominance effects did not differ for mutations impacting the embryo and adult.

Selfing: With a probability equal to the $p_{\text {self }}$ (which we systematically varied from zero to one in increments of 0.2 ) the seed parent was also chosen to be the pollen parent. Otherwise, mating was random, with pollen parents chosen and with replacement in proportion to adult fitness, using the sample() function in $\mathrm{R}(\mathrm{R}$ Core Team 2020). We note that this random mating does not preclude selfing. Therefore, even with $p_{\text {self }}=0$, one of every $N_{e}$ embryos (approximately 0.001 when $\mathrm{N}=1000$, depending on seed survival rates and the variance in post-embryo fitness) is expected to have identical pollen and seed parents. 
Burn in: For all parameter combinations, we forward simulated ten replicates process for 2000 generations, ensuring that populations achieved mutationselection-drift balance by visually examining the variability in the number of deleterious mutations over time and among replicates (Figure S1). For most parameter values, equilibrium was reached within this time frame (Figure S1). However, for recessive mutations in predominantly outcrossing populations (with selfing rates of $0,0.2$, or 0.4 ) this was not enough time to reach equilibrium. For these slowly equilibrating cases, we increased the burn-in period until 3000 generations, at which point equilibrium was largely achieved. Finally, with complete selfing and a non-recessive load with $s=0.1$, the number of deleterious mutations seems somewhat unstable (Figure S1).

Invasion of polyembryony: For each burn in replicate, we ran many introductions of a dominant acting polyembryony allele, introduced at a frequency of $1 / 2 N$, and kept track of the fate of this allele (loss or fixation) for each introduction. Due to computational considerations, we varied the number of introductions from 500 to 1000 for each model of polyembryony (below) for each burn-in replicate. That is, when polyembryony was strongly favored, a given simulation took longer to complete (because fixation from $1 / 2 N$ takes more time than loss from $1 / 2 N)$. By contrast, when polyembryony is not strongly favored, individual simulations are faster (because loss occurs more quickly than fixation) and more precision was needed to distinguish fixation rates from neutrality. The $\mathrm{R}$ ( $\mathrm{R}$ Core Team 2020) code for these forward simulations is available on github https: 


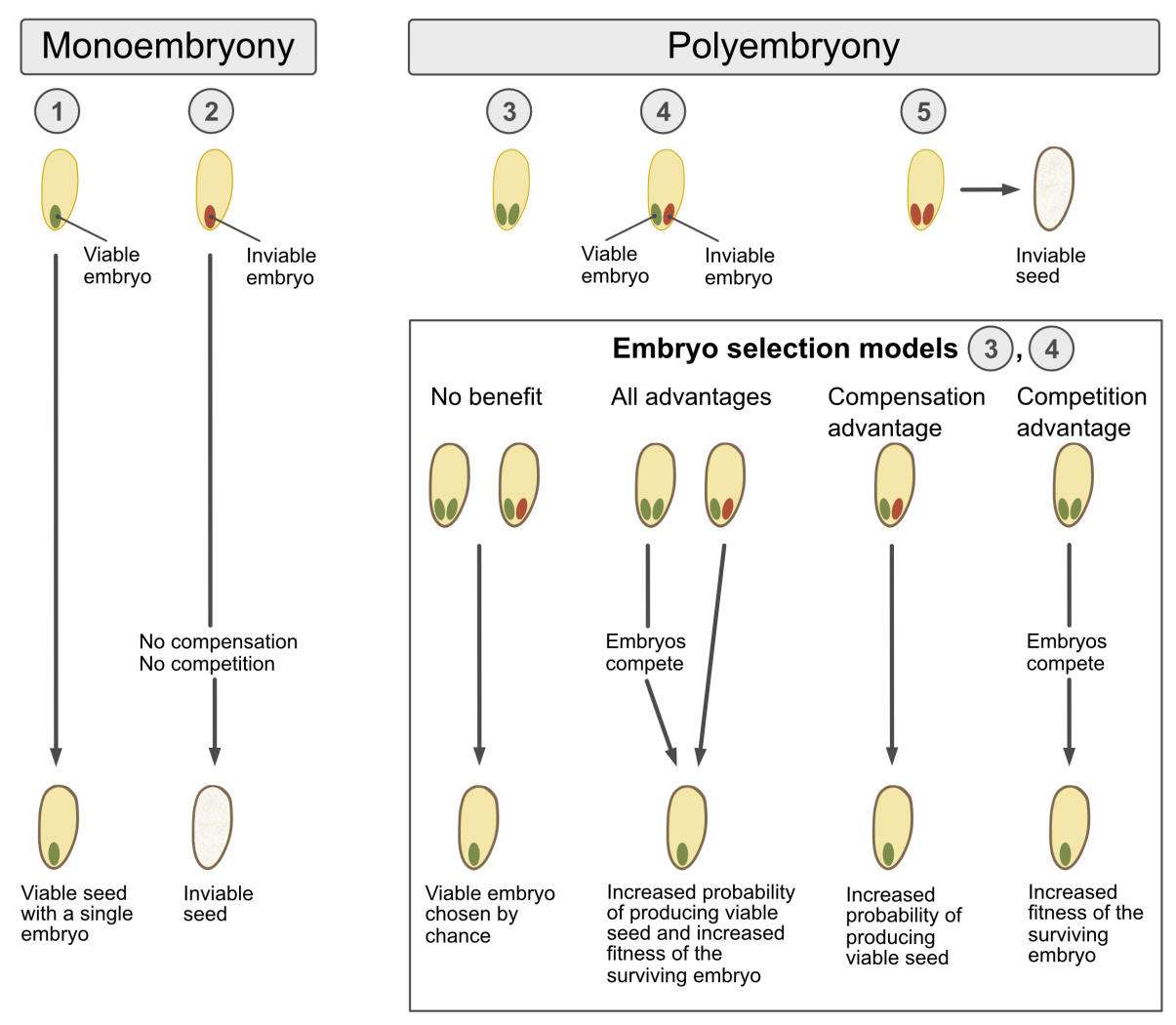

Figure 2: Monoembryony and polyembryony: (A) Under monoembryony, the seed viability is defined by the viability of the single embryo. (B) In simple polyembryony with two embryos, the seed has three possible combinations of viable and inviable embryos. In cases with 1-2 viable embryos, the outcome is defined by the four embryo selection models (see text for details)

//github.com/ybrandvain/polyembryony. competition to the evolution of polyembryony.

The reproductive compensation benefit of polyembryony is that having 
two potential embryos in a seed increases the probability that a seed will contain a viable embryo. Thus, the benefit of reproductive compensation occurs if the survival of at least one embryo ensures a viable seed. We can effectively remove this benefit of polyembryony by allowing seed viability to be determined by survival of an arbitrarily chosen embryo among that seed's two embryos.

The embryo competition benefit of polyembryony is that, if there is any relationship between early embryo viability and adult fitness, mothers can increase their expected inclusive fitness by allowing embryos to compete and the more vigorous embryo to become the dominant embryo. We allow for the benefit of embryo competition by selecting the embryo that makes it to the seed among surviving embryos with probabilities in proportion to their embryonic fitness. We can effectively remove this benefit of polyembryony by randomly choosing a single surviving embryo in a seed to become the dominant embryo and continue development. Factorially combining these options results in four models for the evolution of polyembryony (Figure 2).

All advantages: In this model, each embryo in the seed of a polyembryonic mother survives independently with a probability determined by its embryonic fitness. If only one embryo survives, this embryo develops into the seed, and if both embryos survive, the embryo that develops in the seed is chosen in proportion to the relative embryonic fitness of each embryo (i.e. if both embryos survive, the probability an embryo develops into a seed equals its fitness divided by the sum of the fitness of both surviving embryos. Thus, this model includes both potential benefits of polyembryony. 
Compensation only: In this model, each ovule in the seed of a polyembryonic genotype survives independently with a probability determined by its embryonic fitness. If only one embryo survives, this embryo develops into the seed, and if both embryos survive, the embryo that develops in the seed is chosen at random. As such, polyembryony provides the benefit of increasing the probability that a seed survives, but does not provide the added benefit of embryo competition. This model resembles the case of reproductive compensation (Porcher and Lande 2005), as inviable genotypes can be replaced. This type of selection is much like hard selection - embryo viability is not dependent on the fitness of the other embryo, however embryos with inviable siblings are more likely to become seed than are embryos with viable siblings.

Competition only: In this model, a seed in a polyembryonic genotype survives with a probability equal to the embryonic fitness of an arbitrarily chosen embryo (embryo 1 in our simulation). Thus, if this embryo dies but the other lives, the seed still dies. As such, monoembryonic and polyembryonic genotypes will have the same probability of developing a viable seed (i.e. in both cases seed survival is determined by the fitness of a single random embryo). However, if both embryos survive, the embryo that develops in seed is chosen in proportion to the relative embryonic fitness of each embryo.

No benefit: In this model, seed survival is determined based on the fitness of a random embryo in that seed, as in the embryo competition model, while embryo selection follows the bet-hedging model, in which each embryo in a seed has an equal probability of surviving. As such, there should be no 
advantage of polyembryony. This model acts as a control to ensure that our simulation scheme meets neutral expectations and that our control for each potential benefit of polyembryony is properly implemented.

\section{Results}

\section{Burn-in simulations}

We discuss the results from our burn-in simulations, as they set the scene for the evolution of polyembryony. Throughout the discussion of burn-in results, we focus on mutations impacting embryo fitness, as results for postembryonic fitness follow similar qualitative and quantitative patterns (Figure S1). Genomes saved at the end of the burn-in are available for download here,

Comparison to published analytical results: Before discussing specific results, we evaluate whether our simulations behave sensibly by comparing model output to known analytical results - namely, the expected number of recessive lethal mutations per diploid genome in a panmictic population. Based on classic results of Li and Nei (1972), Gao et al. (2015) show that the expected number of recessive lethals per (diploid) individual in a finite, panmictic population equals $U \sqrt{2 \pi N_{e}}$, where $U$ is the mutation rate per haploid genome, and $N_{e}$ is the effective population size. For the case of recessive embryo lethals in outcrossers, we find a mean of 18.6 mutations per diploid genome, a value remarkably consistent with the predicted value of 18.4 (Compare dashed white line to simulation results in Figure $3 \mathrm{~A}$ ). That 
is, if $U=0.25$, as we are only concerned with mutations impacting embryo fitness (half of total mutations), and $2 N_{e} \approx 1745$, the mean number of surviving embryos across replicates in the final generation. Additional exploratory simulations (not shown) found a consistent agreement with theory across a range of mutation rates.

Novel Burn-in Results: Recessive lethal mutations are effectively purged with predominant selfing (selfing rate $>0.5$ ), while a large number of deleterious mutations accumulate with predominant outcrossing (Figure 3A). Intriguingly, with an intermediate selfing rate of 0.4 , the population appears to reach an equilibrium, relatively modest number of recessive mutations, until this rapidly and dramatically increases, presumably reflecting a transition from effective purging to interference among deleterious mutations (Lande et al. 1994 Porcher and Lande 2016). Across all parameter combinations, the number of deleterious mutations at equilibrium decreased as mutations became more deleterious and more additive (Figure S1A). Additionally, across all dominance and selection coefficients, the number of deleterious alleles in a population decreased with the selfing rate. However, the results for obligate selfers were somewhat unstable with weak selection and non-recessive dominance coefficients.

When mutations are recessive $(h=0)$, mean fitness is lowest with intermediate selfing rates, and is generally highest with high levels of selfing or outcrossing (Figure $3 \mathrm{~B}$ ). This pattern is most pronounced when recessive mutations are lethal $(s=1)$, exceptionally deleterious $(s=0.5)$, or where selection coefficients were drawn from a uniform distribution, and more subtle with a selection coefficient of $s=0.1$ (Figure 3B). By contrast, when mutational effects are additive $(h=0.5)$ or are drawn from a uniform 

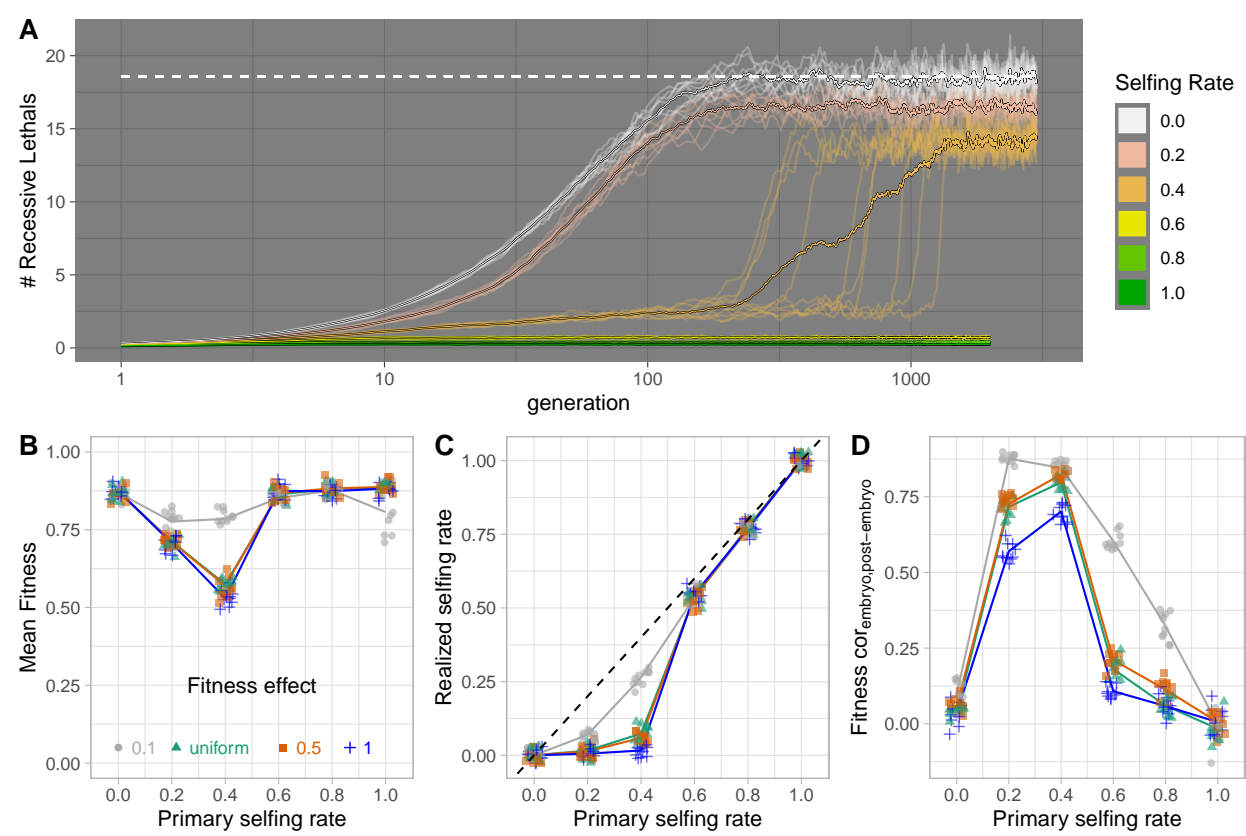

Figure 3: Results from burn-in: (A) The mean number of recessive lethal alleles per haploid genome over time. Each line is one of ten replicates for each selfing rate, designated by color. The dashed white line shows the theoretical expectation for a randomly mating population in our simulation, while the larger colored line shows the mean across replicates. Results with different dominance and selection coefficients are presented in Figure S1. Figures (B-D) show features of the population 'burn-in' populations after the load equilibrates. Points are slightly jittered to show the data - with one value for each replicate simulation for a given combination of selfing rates on the $\mathrm{x}$, and fitness effects of new mutations in color, lines connect means. In $\mathbf{C}$, the one to one line is shown by the dashed black line. All mutations are fully recessive. Results with different dominance coefficients are presented in Figure S2.

distribution, mean fitness increases with the selfing rate, with significantly positive slopes ranging between 0.045, and 0.082 (Figure S2A, Table S1), presumably because selfing increases the variance in fitness, allowing for more effective selection. In these non-recessive cases, mean embryo fitness is roughly similar, regardless of the fitness effects of individual mutations (Fig- 
ure S2, modelling mean fitness $=f($ selfing, $s)$, the p-value for the effect of $s$ is 0.059 and 0.25 , for cases with a uniform and additive load, respectively, Table S2). Reassuringly, this grand mean fitness under obligate outcrossing for non-recessive alleles of 0.78 is in line with Haldane's 1937 classic result that mean fitness equals $e^{-U}$ (where $U$ is the mutation rate per haploid genome, which equals 0.5 divided by two, as half of mutations will impact embryo fitness). Somewhat surprisingly, mean post-embryonic fitness does depend on the selection coefficient (Fig. S2D), suggesting that selection at one life stage impacts outcomes at another as suggested by (Sakai 2019).

With intermediate selfing rates and recessive gene action, we observe a much higher primary than realized selfing rate, suggesting that inbreeding depression underlies much of the embryo death in these cases (Fig. 3C). By contrast, we observe a nearly perfect relationship between primary and realized selfing rates under non-recessivity (Fig. 3B). We observe a strong positive correlation between embryo and post-embryo fitness for recessive gene action and intermediate selfing rates, but no relationship otherwise (Fig. 3D, and Fig. S2D). Together these results support the intuition that if competition acts to remove selfed embryos, this benefit of polyembryony will be most relevant when mutations are recessive.

\section{Invasion of polyembryony}

We compare the fixation probability of a new mutant that confers polyembryony, across all models described above. We find that, when the polyembryony allele fixes, it tends to fix more quickly when polyembryony provides reproductive compensation than when it does not (Fig. 4A, Fig. S4, Table S3). Similarly, polyembryony is most likely to fix when it provides repro- 
ductive compensation - in some cases, single mutations have up to a fifteen percent chance of reaching fixation, a 300-fold increase in the probability, relative to neutral expectations (Fig. $4 \mathrm{~B} \& 4 \mathrm{C}$ ). The benefits of competition alone also favored the evolution of polyembryony, but had a more modest effect - in some cases, single mutations have up to a one percent chance of reaching fixation, a 20 -fold increase in the probability, relative to neutral expectations. Reassuringly, fixation proportions from the no benefits model matched neutral expectations, with approximately $1 / 2 N=0.0005$ introductions resulting in fixation (See Table $\mathrm{S3}$, and compare the solid lines to the dashed line in Figure $4 \mathrm{~B})$.

Other biological parameters such as the selfing rate, and the dominance and selective coefficients of deleterious mutations also impact on the evolution of polyembryony, often depending on their interaction. Below we discuss the effects of selfing rate and additive vs. recessive modes of gene action, noting that results from the uniform mode of gene action are qualitatively similar to the additive model (Fig. S3, Table S3).

The benefit of reproductive compensation strongly favored the evolution of polyembryony for all biological parameters investigated (Fig. 4). Figure $4 \mathrm{C}$ displays the fixation proportions for the compensation models (row two in Fig. 4B) on a linear scale to reveal the effect of selfing rate and selective effects of new mutations.

Under recessivity, the probability of fixation is maximized (approximately 15\%) at intermediate selfing rates, suggesting that polyembryony can evolve to make up for offspring lost to early acting-inbreeding depression. Again assuming recessivity, obligate outcrossing more strongly favors the evolution of polyembryony than does obligate selfing (compare an ap- 


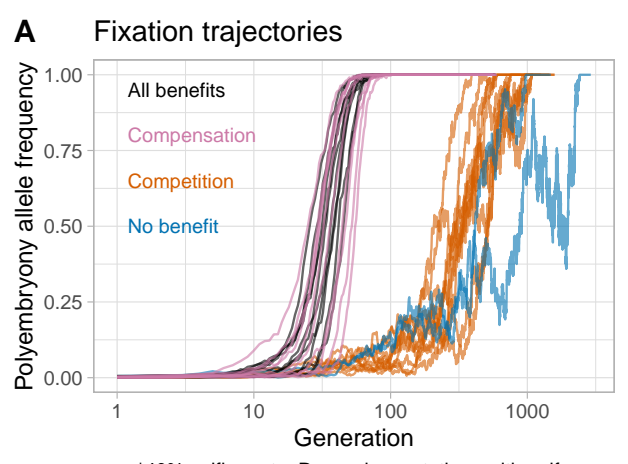

C Proportion fixed (linear scale)

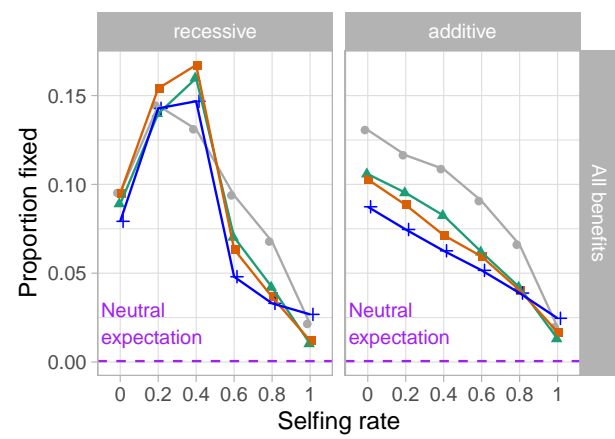

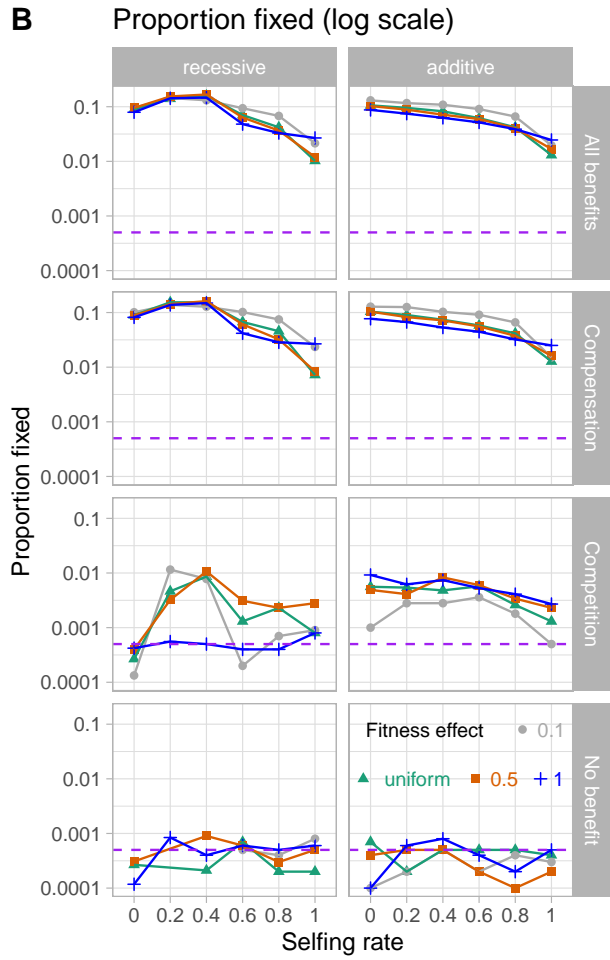

B

Figure 4: The fixation of an allele conferring polyembryony: A) Example trajectories of the fixation of the polyembryony allele with all benefits (black), the benefit of compensation (pink), the benefit of competition (orange), and no benefit (blue). Note that generation on $\mathrm{x}$ increases on the $\log 10$ scale, but specific values are noted with their linear value. B) The proportion of introductions resulting in fixation of the polyembryony allele as a function of the selfing rate (x), the fitness effect of new mutations (color), the mode of gene action (columns), and the benefit of polyembryony (rows). The dashed pink line displays the expectation under neutrality. Note that fixation proportion on y increases on the $\log _{10}$ scale, but specific values are noted with their linear value. C) The proportion of introductions resulting in fixation of the polyembryony allele as a function of the selfing rate (x), the fitness effect of new mutations (color), the mode of gene action (columns), with all the benefits of polyembryony. The values are identical to those in the first row of $\mathbf{B}$, but are presented on a linear scale to highlight the effect of selfing rate on fixation probability. 
proximately $10 \%$ fixation probability under obligate outcrossing to a $2.5 \%$ fixation probability under obligate selfing, Fig. 4C), presumably reflecting the higher within-seed variance in fitness under obligate outcrossing leading to higher impact of polyembryony. The fitness effect of recessive deleterious mutations have only a modest effect on fixation proportion, varying slightly across selfing rate.

However, the compensation model also strongly favors the evolution of polyembryony with an additive load, suggesting that overcoming inbreeding depression is not the only driver of the evolution of polyembryony. (Second row, second column, Figure $4 \mathrm{~B}$ ). In cases with additive gene action, the fixation probability of a polyembryony allele decreases with the selfing rate, again reflecting the lack of within-seed variance in fitness. Additionally, under additivity (or if mutations take their dominance coefficients from a uniform distribution, Table S3, Figure S3 a load composed of highly deleterious mutations is less likely to foster the evolution of polyembryony than a load composed of a larger number of mild mutations (compare $s=1$ (blue) to $s=0.5$ (orange) or s=uniform (teal) to $s=0.1$ (grey), Fig. (4). This surprising result might reflect the fact that while mean fitness does not depend on fitness effects of new mutations, the survival of maternal sib-embryos becomes more dependent on one another as mutational effects get larger (Figure S5). As such, with large effect mutations, a backup embryo is less useful as if one dies the other is likely to die as well.

The benefit of embryo competition also favors the evolution of polyembryony. However, fixation probabilities are approximately five- to ten-fold lower for this model than for the reproductive compensation model. With a recessive load and intermediate selfing rates $(0.20$ or 0.40$)$, the benefit 
of embryo choice results in the fixation of the polyembryony allele in approximately one percent of introductions, a twenty-fold increase relative to the neutral expectation of $0.05 \%$. Somewhat surprisingly, the embryo competition model favors polyembryony for a non-recessive load (Third row, second column of Fig. 4B), even though embryo fitness was uncorrelated with post-embryo fitness in these models (Fig. S2). This likely reflects the benefit of producing grand-children with higher embryonic fitness who will out-compete their siblings (analogous to models of "runaway sexual selection" Kirkpatrick 1982). Under both additivity and a uniform distribution of mutational effects, the probability of fixation of an allele conferring competitive polyembryony is greatest in predominantly outcrossing populations (selfing rates of 0.40 or less), decreasing as the selfing rate increases. Here, the probability of fixation is greatest when the load is composed of alleles of large effect, a result that runs counter to that found in the compensation model with an additive load.

All benefits results in fixation probabilities qualitatively similar to the reproductive compensation model (Fig. S3, Table S3) - reflecting the importance of the benefits of reproductive compensation, to the evolution of polyembryony.

No benefits results in fixation probabilities consistent with neutral expectations (Fig. S3, Table S3).

Evolutionary consequences of polyembryony

We compare how different models of the evolution of polyembryony shape key features of a population, including the proportion of surviving seeds, 
the realized selfing rate and the architecture of genetic load. Although a strict version of the competition only model is unlikely to occur in nature, its inclusion allows us to distinguish the individual effects of competition and compensation when both would be operating in nature (i.e. the all benefits model). Because results were qualitatively similar across all selection coefficients (save the decrease in fitness with recessive mutations, $s=0.1$ and high selfing rates, which did not always converge Fig. S1), and because results from the additive model and the uniformly distributed dominance coefficient model did not differ qualitatively, we focus on results from the cases in which the selection coefficients of new mutations are selected at random from a uniform distribution, exploring cases in which mutations are recessive or additive (Figure 5).

Curiously, the benefit of embryo competition alone did not impact the realized selfing rate (Fig. 5), even with recessive mutations and intermediate selfing rates. This result is a consequence of features of both our model and biological reality. Specifically, there are limited opportunities for competition between selfed and outcrossed embryos in a seed (Williams 2007), as this only occurs with a probability equal to two times the variance in the selfing rate (the probability that exactly one of two embryos is from a self-fertilization event) times the probability that both are destined to survive. By contrast, with a recessive load a benefit of compensation decreases the realized selfing rate, and increases the number of mutations impacting embryo fitness in partially selfing populations (Fig. 5).

The benefit of compensation (in both the compensation and all benefits model) resulted in a strong increase in seed survival. Under a recessive load, this effect was maximized with intermediate selfing rates, while it decreased steadily with selfing rate under a (partially) additive load. By selecting for 

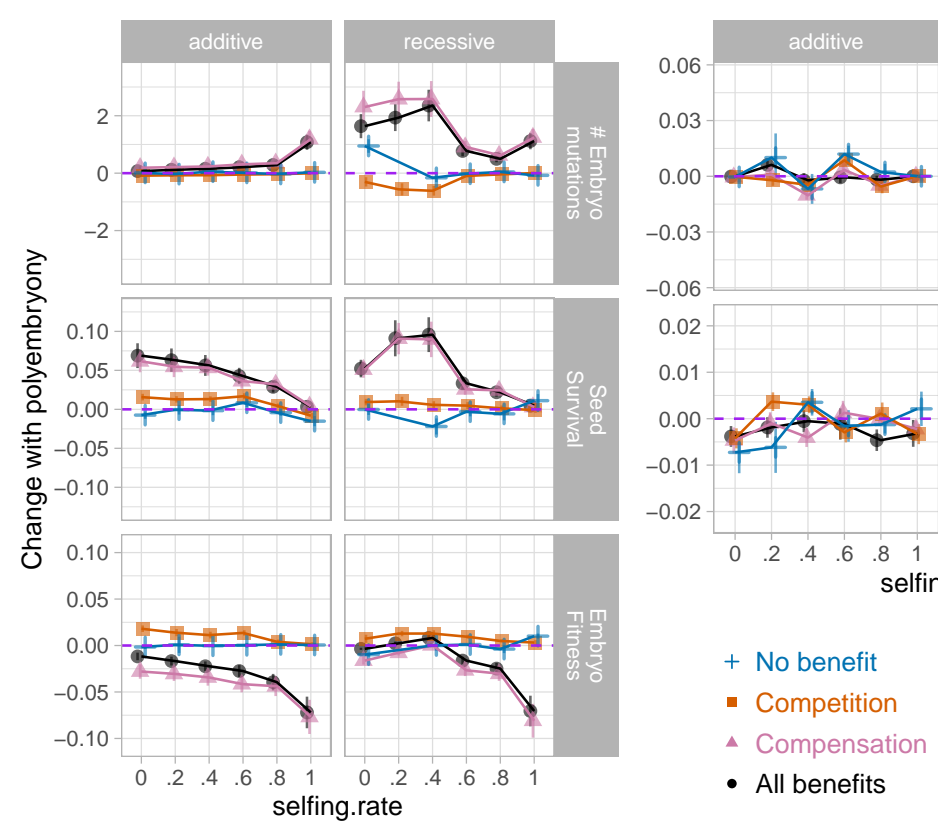

Figure 5: The evolutionary impact of polyembryony. How the evolution of polyembryony impacts the per individual number of mutations impacting embryo fitness, expected seed survival, mean embryo fitness, the realized selfing rate, and mean post-embryo fitness (rows), when mutations are additive or recessive (columns), across selfing rates (x-axis), for each model of polyembryony (color).

higher fitness embryos, the benefit of competition alone subtly increased seed survival for all models of dominance investigated so long as the selfing

the surviving seeds subtly increases with the benefit of embryo competition, but decreases with compensation. These benefits appear to act additively, such that the expected embryo fitness decreases in the all benefits model but does so less severely than in the compensation model.

Regardless of the mode of gene action, the competition model does not increase the expected post-embryo fitness of surviving seeds (Fig. 5). While 
post-embryo fitness modestly increases with the evolution of polyembryony under a model of competition with intermediate selfing rates and a recessive load, this increase pales in comparison to the benefits of higher seed viability which accompanies reproductive compensation. Together, these lines of evidence suggest that polyembryony does not evolve as a mechanism to prevent self-fertilization, and is not analogous to the system of self-incompatibility observed in angiosperms.

Additional evidence against the hypothesis that the embryonic lethal system evolves as an SI-like mechanism comes from the allele frequency spectrum of deleterious mutations (Fig. 5). If the prevention of the formation of inviable selfed seeds by eliminating selfed embryos favored a system to destroy selfed embryos, we would expect an increase in very rare recessive lethal alleles so as to ensure the death of selfed embryos. Contrary to this expectation, we see no such shift in the frequency spectrum. Figure 6 shows that the allele frequency spectrum is comparable in the no benefit and competition model, arguing against the idea that competition favored selfsacrifice in the form of an excess of rare recessive lethals. By contrast, there is a slight increase in the count of deleterious recessive mutations across all frequency classes in the compensation and all benefits models, reflecting the relaxation of embryo selection in these cases.

\section{Discussion}

We present four models to test the plausibility of the compensation and competition theories for the evolution of polyembryony. We find that the evolutionary benefit of compensation - that is, the opportunity for a backup embryo to replace an inviable one - strongly favors the evolution of polyem- 


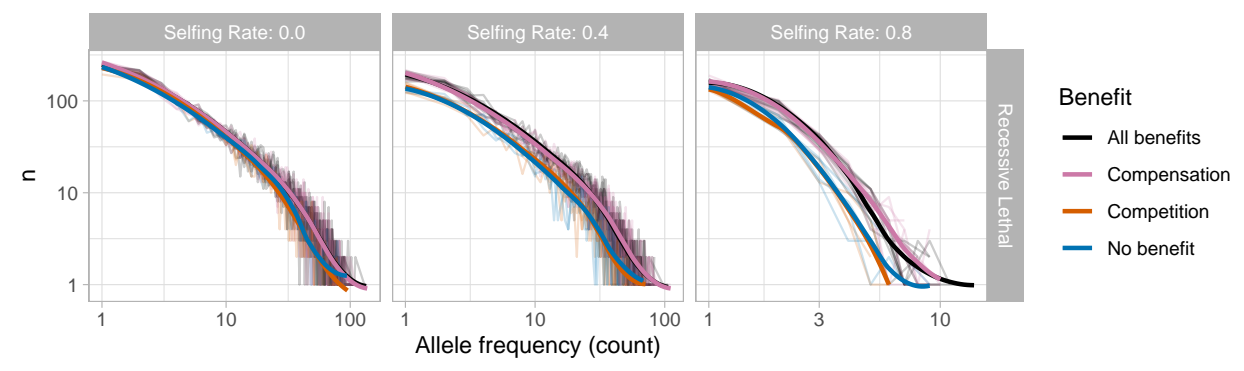

Figure 6: The allele frequency spectrum for embryo acting allele following the evolution of polyembryony under the recessive lethal model for a selfing rate of $0.00,0.40$, and 0.80 (left to right). Lines display averages of ten simulation replicates, and colors note the model of polyembryony. Note that the $\mathrm{x}$ axis with a selfing rate of 0.80 (right panel) is truncated relative to the other selfing rates, reflecting the effective purging of early acting recessive mutations with high selfing rates.

bryony. Relative to neutral expectations, the benefit of compensation results in between a twenty-fold increase in fixation probability above the neutral expectation with high selfing rates, and a two hundred-fold increase with intermediate to low selfing rates and a recessive load, all across a broad range of selection and dominance coefficients. By contrast, the benefit of embryo competition more weakly favored the evolution of polyembryony, resulting in between a zero-fold increase with high selfing rates, and a twenty-fold increase, with intermediate to low selfing rates and a recessive load, relative to neutral expectations.

Our work highlights the previously underappreciated result that the consequences of polyembryony depend on its function. When polyembryony functions as a compensation mechanism, mean embryo fitness is reduced, but the probability of seed survival increases, consistent with previous work (Latta 1995; Porcher and Lande 2005). By contrast, competition between embryos alone increases embryo fitness, but has a negligible effect on seed 
survival, in line with models oof competition alone (Latta 1995). With a recessive load, the benefit of compensation acts to decrease the effective selfing rate, while competition did not. With both the benefits of competition and compensation the evolutionary consequences of polyembryony is somewhere in between but is often closer to those expected from compensation.

The limited role of embryo competition in the evolution of polyembryony: It has long been assumed that a major benefit of polyembryony is that it provides an opportunity for embryos to compete (Sarvas 1962 , Koski 1971), and to create high fitness offspring offspring. Not only was the benefit of competition a comparatively weak force in the evolution of polyembryony, but it did not reliably increase seed fitness. In fact, under most selfing rates and dominance coefficients, competition more strongly favored the evolution of polyembryony with an additive load (in which there is no relationship between embryo and post embryo fitness) than a recessive load (in which there was such a relationship). This is surprising because there is a limited scope for selection on polyembryony when it cannot affect post-embryo fitness. In this case, selection on polyembryony only occurs within polyembryonic seeds themselves, and, since the embryos' maternal genomes are identical, only among the paternal genomes. Like runaway sexual selection (Fisher 1915), the automatic transmission advantage of selfing (Fisher 1941), or meiotic drive (Rhoades 1942), embryo competition is an example of a selective advantage that does not make a population necessarily more adapted to its environment.

Why doesn't embryo competition effectively remove selfed offspring and increase post-embryonic fitness (and could it ever)? 
We considered only two embryos and only allowed for competition if both embryos were destined to live in our model of embryo competition. As such, embryo competition can only weed out selfed offspring when one seed is selfed and the other is not and both seeds are destined to live. Because predominant selfing (selfing rate $>0.5$ ) purges the recessive load, and predominant outcrossing (selfing rate $<0.5$ ) generates large inbreeding depression, in most cases in which selfed and outcrossed embryos could compete, their fitness is either nearly equal or the selfed embryo is destined to die. As such, embryo competition does not offer a more refined view into postembryo fitness than is automatically accounted for by "hard selection" on seed viability imposed in our model. Our observation that embryo competition leads to more competitive embryos rather than higher fitness plants is consistent with the claim of McCoy and Haig (2020) that Goodhart's law - 'When a measure becomes a target it ceases to be a good measure' - can undermine effective embryo selection. Despite our focus on the evolution of polyembryony, these results apply broadly and suggest that verbal models predicting that selective embryo abortion could limit the mating costs of selfing in plants with mixed mating systems (e.g. Huang et al. 2020), require more rigorous scrutiny.

Nonetheless, it is possible that pure "soft selection" (Wallace 1968, 1975) on embryos could reliably increase post-embryo fitness. However we had trouble implementing this model computationally (e.g. we could not define the allele frequency spectrum of alleles determining success in soft selection before embryo competition evolved), nor could we map this onto a plausible biological mechanism. Nonetheless, this challenge could reflect a shortcoming in our imagination, rather than a biological impossibility. Additionally, we note that even if the benefits of compensation initially favored the evo- 
lution of polyembryony, it is possible that the evolution of polyembryony was followed by novel recessive mutations experiencing soft selection and that therefore the benefits of competition could maintain but not drive the evolution of polyembryony.

The embryo lethal system: Since Buchholz (1922), it has been argued that the embryo-lethal system, an apparently coordinated process of embryo death, could achieve a similar function to angiosperm self-incompatibility in the self-compatible gymnosperms. That is, intentional, coordinated death in the embryo stage would give way to highly outbred surviving adults (Sarvas 1962, Koski 1971). This would be an altruistic act in which an embryo sacrifices its predictably low fitness for a half sibling. We did not observe the evolution of an embryo lethal system in response to the evolution of polyembryony, as would be expected if polyembryony favored altruistic selfdestruction of more inbred embryos (e.g. we did not see a change in the allele frequency spectrum towards an excess of low-frequency recessive mutations). However, by relaxing selection on embryo viability, embryo compensation could indirectly result in an increase in the number of highly deleterious recessive mutations impacting embryo fitness. As such, while we cannot exclude possibilities which we did not model (e.g. pure soft selection, above, or pleiotropy across life stages (below)), it appears that the embryo lethal system could reflect an elevated load tolerance rather than an exquisite adaptation (Gould and Lewontin 1979), as Williams (2007) argued forcefully based on developmental and genetic evidence.

Which has driven the evolution of polyembryony - Compensation or competition? We find that the benefit of embryo compensation favors 
the evolution of polyembryony more strongly than does embryo competition. However, we caution that whether compensation or competition have actually favored the evolution of polyembryony depends on their biological plausibility and whether they reflect effective solutions to the problems they address. That is, we must consider biological processes outside of our model as we interpret our model results. For example, embryo competition could perhaps be most effectively achieved by placing more embryos in a seed, while compensation could be more effectively achieved by producing more seeds per plant.

Our models provide competing testable predictions to distinguish between predictions of the compensation and competition model at within seed level, for simple polyembryony, assuming no pleiotropic effects. For example, we show that the evolution of polyembryony and its consequences depend on the selfing-rate and dominance coefficient. Specifically, with a recessive genetic load, embryo competition most strongly favors the evolution of polyembryony at intermediate selfing rates (Fig. $4 \mathrm{~B}, \mathrm{C})$. The estimates of selfing rates for modern conifers can reach 0.30 - 0.60 (Sarvas 1962; Sorensen 1982), a range that favors polyembryony. We note, of course, that estimates of the primary selfing rate from extant conifers rate may differ substantially from the primary selfing rates of the population in which polyembryony arose.

Additionally, the two models make subtly different predictions about the difference between the realized and primary selfing rate. Relative to a monoembryonic ancestral population, polyembryony favored by embryo competition alone does not result in decrease in the difference between realized and primary selfing rates. By contrast, with a recessive load and intermediate selfing rates, polyembryony favored by compensation strongly amplified the 
difference between the realized and primary selfing rates. In nature, differences between primary and realized selfing rates are often observed in species „with simple polyembryony (Lindgren 1975, Sorensen 1982 ; Kärkkäinen and Savolainen 1993; Lande et al. 1994), further emphasizing the probable role of compensation in the evolution and maintenance of polyembryony.

Alternative Models for the Evolution of Polyembryony: We assumed no pleiotropy across life stages - that is, mutations either impacted embryo or post embryo fitness. However, this is clearly untrue. For example, severe loss of function mutations in key genes would likely decrease both embryo and seed fitness. Preliminary investigations of this scenario (not shown) showed that this model so strongly favored the evolution of polyembryony that it was theoretically trivial, and we therefore did not pursue this possibility in greater detail. Theoretical triviality does not imply biological irrelevance, and as such we cannot exclude this biologically plausible model.

On the other hand, an allele could antagonistically increase embryo fitness while decreasing post embryonic fitness. When such a mutation occurs with embryo competition, it could generate an ontogenic conflict. Empirical studies, e.g. mapping and measuring of inbreeding depression at different life stages (Koelewijn 1998), comparing gene expression across embryo development and later life stages (Raherison et al. 2012), and signatures of negative and positive selection in such genes would be valuable to further evaluate the potential importance of pleiotropy in the evolution of polyembryony.

Competition, compensation and conflict in a pine nutshell: Gymnosperm seed with a maternal haploid megagametophyte, multiple geneti- 
cally distinct embryos, genetically identical (cleavage) embryos, and strong inbreeding depression is a stage of evolutionary drama that deserves more attention, and we hope that the provided model will be used to broaden the investigations on the evolutionary dynamics outside the angiosperm sphere. For example, in contrast to the opportunity for altruism to favor the embryolethal system, polyembryony also provides avenues for parental and embryonic conflict.

In simple polyembryony, embryos are potentially derived from different sires. A paternal genome carrying a mutation that sabotaged rival embryos carrying different paternal genomes could possess a net advantage even if doing so would reduce the probability that a viable seed is formed at all. Sabotage and anti-sabotage alleles would only be beneficial when expressed in a particular parental genome, so genomic imprinting that prevented expression in the wrong parental genome would also be advantageous.

Conifers and other gymnosperms provide unique opportunities to test key questions of plant mating system evolution and evolutionary conflict from a novel angle, especially now that their genomic resources are no longer seriously hindered by their large genome sizes. From the practical/empirical perspective, large seed size and gametophytic tissue allow easy identification of maternal haplotypes and alleles. Thus expression patterns and genetic diversity for example in potentially imprinted genes should be easy to quantify and identify in many conifer species. 


\section{Acknowledgments}

TP received funding from Academy of Finland (grant nrs. 287431 and 319313) and acknowledges CSC, IT Center For Science for computational resources. AH was funded through the University of Minnesota Doctoral Dissertation Fellowship. The authors thank Outi Savolainen for insightful comments on the manuscript.

Agapito-Tenfen, S. Z., N. Steiner, M. P. Guerra, and R. O. Nodari. 2012. Patterns of polyembryony and frequency of surviving multiple embryos of the brazilian pine Araucaria angustifolia. Australian Journal of Botany 59:749-755.

Bramlett, D. L., and F. E. Bridgwater. 1986. Segregation of recessive embryonic lethal alleles in a F1 population of virginia pine. In IUFRO Conference on Breeding Theory, Williamburg Va.

Buchholz, J. T. 1922. Developmental selection in vascular plants. Botanical Gazzette 73:249-286.

Chamberlain, C. J. 1966. Gymnosperms: Structure and Evolution; With 397 Fig. Dover Publ.

Dillard, A. 1974. Pilgrim at Tinker Creek. Literature (Harper \& Row). HarperPerennial.

Dogra, P. D. 1967. Seed sterility and disturbances in embryogeny in conifers with particular reference to seed testing and tree breeding in pinaceae. Studia forestalia Suecica pages 1-97.

Fisher, R. A. 1915. The evolution of sexual preference. Eugenics Review 


\section{7:184-192.}

—. 1941. Average excess and average effect of a gene substitution. Annals of Eugenics 11:53-63.

Forbes, L. S., and D. W. Mock. 1998. Parental optimism and progeny choice: When is screening for offspring quality affordable. Journal of Theoretical Biology 192:3-14.

Forbes, S. 2009. Portfolio theory and how parent birds manage investment risk. Oikos 118:1561-1569.

Ganeshaiah, K. N., R. Uma Shaanker, and N. V. Joshi. 1991. Evolution of polyembryony: Consequences to the fitness of mother and offspring. Journal of Genetics 70:103-127.

Gao, Z., D. Waggoner, M. Stephens, C. Ober, and M. Przeworski. 2015. An estimate of the average number of recessive lethal mutations carried by humans. Genetics 199:1243-1254.

Gould, S. J., and R. C. Lewontin. 1979. The spandrels of san marco and the panglossian paradigm: a critique of the adaptationist programme. Proceedings of the Royal Society B: Biological Sciences 205:581-598.

Haig, D. 1992. Brood reduction in gymnosperms. Pages 63-84 in M. Elgar and B. Crespi, eds. Cannibalism: ecology and evolution among diverse taxa. Oxford University Press, Oxford.

Haldane, J. B. S. 1937. The effect of variation on fitness. American Naturalist $71: 337-349$.

Hedrick, P. W., O. Savolainen, and K. Karkkainen. 1999. Factors influencing the extent of inbreeding depression: an example from scots pine. Heredity 82 Pt 4:441-450.

Huang, Q., W. Wang, S. C. H. Barrett, and M. Ren. 2020. Plasticity in se- 
lective embryo abortion may limit the mating costs of geitonogamy in selfcompatible plants: a hypothesis. American Journal of Botany 107:390393.

Husband, B. C., and D. W. Schemske. 1996. Evolution of the magnitude and timing of inbreeding depression in plants. Evolution 50:54-70.

Kärkkäinen, K., V. Koski, and O. Savolainen. 1996. Geographical variation in the inbreeding depression of scots pine. Evolution 50:111-119.

Kärkkäinen, K., and O. Savolainen. 1993. The degree of early inbreeding depression determines the selfing rate at the seed stage: model and results from Pinus sylvestris (scots pine). Heredity 71:160-166.

Kirkpatrick, M. 1982. Sexual selection and the evolution of female choice. Evolution 36:1-12.

Klekowski, E. J. 1982. Genetic load and soft selection in ferns. Heredity 49:191-197.

Koelewijn, H. P. 1998. Effects of different levels of inbreeding on progeny fitness in Plantago coronopus. Evolution 52:692-702.

Koski, V. 1971. Embryonic lethals of Picea abies and Pinus sylvestris. Metsäntutkimuslaitos.

Lakshmanan, K. K., and K. B. Ambegaokar. 1984. Polyembryony. Pages 445-474 in B. M. Johri, ed. Embryology of Angiosperms. Springer Berlin Heidelberg, Berlin, Heidelberg.

Lande, R., D. W. Schemske, and S. T. Schultz. 1994. High inbreeding depression, selective interference among loci, and the threshold selfing rate for purging recessive lethal mutations. Evolution 48:965-978.

Latta, R. G. 1995. The effects of embryo competition with mixed mating on the genetic load in plants. Heredity 75:637-643. 
Li, W. H., and M. Nei. 1972. Total number of individuals affected by a single deleterious mutation in a finite population. American Journal of Human Genetics 24:667-679.

Lindgren, D. 1975. The relationship between self-fertilization, empty seeds and seeds originating from selfing as a consequence of polyembryony. Studia Forestalia Suecica 126:1-24.

Lynch, M., and B. Walsh. 1998. Genetics and analysis of quantitative traits: Sinauer. Sunderland.

McCoy, D. E., and D. Haig. 2020. Embryo selection and mate choice: Can 'honest signals' be trusted? Trends in Ecology and Evolution 35:308-318.

Mikkola, L. 1969. Observations on interspecific sterility in picea. Annales Botanici Fennici 6:285-339.

Mock, D. W. 1984. Siblicidal aggression and resource monopolization in birds. Science 225:731-733.

O'Connell, L. M., and K. Ritland. 2005. Post-pollination mechanisms promoting outcrossing in a self-fertile conifer, Thuja plicata (cupressaceae). Canadian Journal of Botany 83:335-342.

Porcher, E., and R. Lande. 2005. Reproductive compensation in the evolution of plant mating systems. New Phytologist 166:673-684.

—. 2016. Inbreeding depression under mixed outcrossing, selffertilization and sib-mating. BMC Evolutionary Biololgy 16:105.

R Core Team. 2020. R: A Language and Environment for Statistical Computing. R Foundation for Statistical Computing, Vienna, Austria.

Raherison, E., P. Rigault, S. Caron, P.-L. Poulin, B. Boyle, J.-P. Verta, I. Giguère, C. Bomal, J. Bohlmann, and J. MacKay. 2012. Transcriptome profiling in conifers and the PiceaGenExpress database show patterns 
of diversification within gene families and interspecific conservation in vascular gene expression. BMC Genomics 13:434.

Rhoades, M. M. 1942. Preferential segregation in maize. Genetics 27:395407.

Sakai, S. 2019. Maintenance of high inbreeding depression in selfing populations: Effects of coupling of early- and Late-Acting mutations. bioRxiv page 748699 .

Sarvas, R. 1962. Investigations on the flowering and seed crop of Pinus silvestris. Metsatieteellisen tutkimuslaitoksen julkaisuja .

Saxton, W. T. 1934. Notes on conifers: IX. the ovule and embryogeny of widdringtonia. Annals of Botany 48:429-431.

Schnarf, K. 1937. Anatomie der Gymnospermen-Samen, vol. 10. Gebr. Borntraeger.

Sorensen, F. C. 1982. The roles of polyembryony and embryo viability in the genetic system of conifers.

Wallace, B. 1968. Polymorphism, population size and genetic load, in "population biology and Evolution"(RC lewontin, ed.) .

—. 1975. Hard and soft selection revisited. Evolution 29:465-473.

Williams, C. G. 2007. Re-thinking the embryo lethal system within the pinaceae. Canadian Journal of Botany 85:667-677.

- 2008. Selfed embryo death in Pinus taeda: a phenotypic profile. New Phytologist 178:210-222.

Williams, C. G., and O. Savolainen. 1996. Inbreeding depression in conifers: Implications for breeding strategy. Forest Science 42:102-117.

Willson, M. F., and N. Burley. 1983. Mate Choice in Plants: Tactics, Mechanisms, and Consequences. Princeton University Press. 
bioRxiv preprint doi: https://doi.org/10.1101/2020.11.17.387340; this version posted November 17,2020 . The copyright holder for this preprint (which was not certified by peer review) is the author/funder, who has granted bioRxiv a license to display the preprint in perpetuity. It is made available under aCC-BY-NC-ND 4.0 International license. 
Table S1: Slope of the relationship between selfing rate and mean embryo fitness after burn-ins for non-recessive variants. All t values are associated with 59 degrees of freedom.

\begin{tabular}{|rrrrrrr|}
\hline $\mathbf{h}$ & $\mathbf{s}$ & estimate & lower 95\% CI & upper 95\% CI & $t$ & p-value \\
\hline 0.5 & 0.1 & 0.054 & 0.031 & 0.076 & 4.719 & 0.000015 \\
0.5 & 0.5 & 0.085 & 0.076 & 0.094 & 19.114 & $<10-11$ \\
0.5 & 1 & 0.051 & 0.039 & 0.062 & 8.600 & $<10-11$ \\
0.5 & uniform & 0.082 & 0.072 & 0.091 & 16.413 & $<10-11$ \\
\hline uniform & 0.1 & 0.045 & 0.015 & 0.074 & 2.980 & 0.004203 \\
uniform & 0.5 & 0.078 & 0.068 & 0.088 & 15.313 & $<10-11$ \\
uniform & 1 & 0.065 & 0.055 & 0.076 & 12.021 & $<10-11$ \\
uniform & uniform & 0.083 & 0.074 & 0.091 & 19.445 & $<10-11$ \\
\hline
\end{tabular}

Table S2: Effect of selection coefficient on mean fitness following burn in for non-recessive variants.

\begin{tabular}{|rrrr|}
\hline $\mathbf{h}$ & estimate & $F_{3,225}$ & $\mathbf{p}$-value \\
\hline 0.5 & 0.054 & 1.39 & 0.059 \\
uniform & 0.083 & 2.52 & 0.247 \\
\hline
\end{tabular}


Table S3: The proportion of introductions of the polyembryony allele resulting in fixation.

\begin{tabular}{|lllrrrr|}
\hline$p_{\text {self }}$ & $\mathbf{s}$ & $\mathbf{h}$ & All benefits & Compensation & Competition & No benefit \\
\hline 0 & uniform & uniform & $0.1084(\mathrm{n}=5000)$ & $0.1025(\mathrm{n}=10000)$ & $0.0041(\mathrm{n}=10000)$ & $0.0012(\mathrm{n}=10000)$ \\
0 & uniform & recessive & $0.089(\mathrm{n}=5000)$ & $0.08937(\mathrm{n}=9500)$ & $0.00027(\mathrm{n}=7500)$ & $0.00027(\mathrm{n}=7500)$ \\
0 & uniform & additive & $0.1058(\mathrm{n}=5000)$ & $0.1038(\mathrm{n}=10000)$ & $0.0056(\mathrm{n}=10000)$ & $7 \mathrm{e}-04(\mathrm{n}=10000)$ \\
0 & 0.1 & uniform & $0.129(\mathrm{n}=5000)$ & $0.131(\mathrm{n}=10000)$ & $0.0017(\mathrm{n}=10000)$ & $2 \mathrm{e}-04(\mathrm{n}=10000)$ \\
0 & 0.1 & recessive & $0.09517(\mathrm{n}=6000)$ & $0.10129(\mathrm{n}=7000)$ & $0.00013(\mathrm{n}=7500)$ & $0(\mathrm{n}=6500)$ \\
0 & 0.1 & additive & $0.1306(\mathrm{n}=5000)$ & $0.128(\mathrm{n}=10000)$ & $0.001(\mathrm{n}=10000)$ & $1 \mathrm{e}-04(\mathrm{n}=10000)$ \\
0 & 0.5 & uniform & $0.1128(\mathrm{n}=5000)$ & $0.0997(\mathrm{n}=10000)$ & $0.0051(\mathrm{n}=10000)$ & $4 \mathrm{e}-04(\mathrm{n}=10000)$ \\
0 & 0.5 & recessive & $0.095(\mathrm{n}=5000)$ & $0.0885(\mathrm{n}=10000)$ & $4 \mathrm{e}-04(\mathrm{n}=7500)$ & $0.00031(\mathrm{n}=6500)$ \\
0 & 0.5 & additive & $0.1028(\mathrm{n}=5000)$ & $0.1037(\mathrm{n}=10000)$ & $0.0049(\mathrm{n}=10000)$ & $4 \mathrm{e}-04(\mathrm{n}=10000)$ \\
0 & 1 & uniform & $0.0844(\mathrm{n}=5000)$ & $0.0875(\mathrm{n}=10000)$ & $0.0049(\mathrm{n}=10000)$ & $0.001(\mathrm{n}=10000)$ \\
0 & 1 & recessive & $0.0792(\mathrm{n}=5000)$ & $0.0817(\mathrm{n}=10000)$ & $0.00042(\mathrm{n}=9500)$ & $0.00012(\mathrm{n}=8500)$ \\
0 & 1 & additive & $0.0874(\mathrm{n}=5000)$ & $0.077(\mathrm{n}=10000)$ & $0.0092(\mathrm{n}=10000)$ & $1 \mathrm{e}-04(\mathrm{n}=10000)$ \\
0.2 & uniform & uniform & $0.0946(\mathrm{n}=5000)$ & $0.0885(\mathrm{n}=10000)$ & $0.0033(\mathrm{n}=10000)$ & $2 \mathrm{e}-04(\mathrm{n}=10000)$ \\
0.2 & uniform & recessive & $0.1398(\mathrm{n}=5000)$ & $0.1539(\mathrm{n}=10000)$ & $0.00462(\mathrm{n}=6500)$ & $0(\mathrm{n}=9000)$ \\
0.2 & uniform & additive & $0.0952(\mathrm{n}=5000)$ & $0.0901(\mathrm{n}=10000)$ & $0.0054(\mathrm{n}=10000)$ & $2 \mathrm{e}-04(\mathrm{n}=10000)$
\end{tabular}




\begin{tabular}{|lllrrrr|}
\hline$p_{\text {self }}$ & $\mathbf{s}$ & $\mathbf{h}$ & All benefits & Compensation & Competition & No benefit \\
\hline 0.2 & 0.1 & uniform & $0.1178(\mathrm{n}=5000)$ & $0.1211(\mathrm{n}=10000)$ & $0.0015(\mathrm{n}=10000)$ & $3 \mathrm{e}-04(\mathrm{n}=10000)$ \\
0.2 & 0.1 & recessive & $0.14436(\mathrm{n}=5500)$ & $0.138(\mathrm{n}=6000)$ & $0.01154(\mathrm{n}=6500)$ & $0(\mathrm{n}=7000)$ \\
0.2 & 0.1 & additive & $0.1164(\mathrm{n}=5000)$ & $0.1258(\mathrm{n}=10000)$ & $0.0028(\mathrm{n}=10000)$ & $2 \mathrm{e}-04(\mathrm{n}=10000)$ \\
0.2 & 0.5 & uniform & $0.0912(\mathrm{n}=5000)$ & $0.089(\mathrm{n}=10000)$ & $0.0048(\mathrm{n}=10000)$ & $5 \mathrm{e}-04(\mathrm{n}=10000)$ \\
0.2 & 0.5 & recessive & $0.154(\mathrm{n}=5000)$ & $0.1427(\mathrm{n}=10000)$ & $0.00322(\mathrm{n}=9000)$ & $0(\mathrm{n}=8500)$ \\
0.2 & 0.5 & additive & $0.0884(\mathrm{n}=5000)$ & $0.0826(\mathrm{n}=10000)$ & $0.0041(\mathrm{n}=10000)$ & $5 \mathrm{e}-04(\mathrm{n}=10000)$ \\
0.2 & 1 & uniform & $0.0808(\mathrm{n}=5000)$ & $0.0672(\mathrm{n}=10000)$ & $0.0055(\mathrm{n}=10000)$ & $4 \mathrm{e}-04(\mathrm{n}=10000)$ \\
0.2 & 1 & recessive & $0.1428(\mathrm{n}=5000)$ & $0.1378(\mathrm{n}=10000)$ & $0.00056(\mathrm{n}=9000)$ & $0.00084(\mathrm{n}=9500)$ \\
0.2 & 1 & additive & $0.0746(\mathrm{n}=5000)$ & $0.0669(\mathrm{n}=10000)$ & $0.0062(\mathrm{n}=10000)$ & $6 \mathrm{e}-04(\mathrm{n}=10000)$ \\
0.4 & uniform & uniform & $0.0762(\mathrm{n}=5000)$ & $0.0736(\mathrm{n}=10000)$ & $0.004(\mathrm{n}=10000)$ & $2 \mathrm{e}-04(\mathrm{n}=10000)$ \\
0.4 & uniform & recessive & $0.1598(\mathrm{n}=5000)$ & $0.1534(\mathrm{n}=10000)$ & $0.0086(\mathrm{n}=10000)$ & $0.00021(\mathrm{n}=9500)$ \\
0.4 & uniform & additive & $0.0824(\mathrm{n}=5000)$ & $0.0738(\mathrm{n}=10000)$ & $0.0048(\mathrm{n}=10000)$ & $5 e-04(\mathrm{n}=10000)$ \\
0.4 & 0.1 & uniform & $0.105(\mathrm{n}=5000)$ & $0.109(\mathrm{n}=10000)$ & $0.0017(\mathrm{n}=10000)$ & $1 \mathrm{e}-04(\mathrm{n}=10000)$ \\
0.4 & 0.1 & recessive & $0.131(\mathrm{n}=5000)$ & $0.1275(\mathrm{n}=10000)$ & $0.00778(\mathrm{n}=9000)$ & $0(\mathrm{n}=8500)$ \\
0.4 & 0.1 & additive & $0.1086(\mathrm{n}=5000)$ & $0.103(\mathrm{n}=10000)$ & $0.0028(\mathrm{n}=10000)$ & $5 e-04(\mathrm{n}=10000)$ \\
0.4 & 0.5 & uniform & $0.071(\mathrm{n}=5000)$ & $0.0681(\mathrm{n}=10000)$ & $0.0053(\mathrm{n}=10000)$ & $3 \mathrm{e}-04(\mathrm{n}=10000)$
\end{tabular}




\begin{tabular}{|lllrrrr|}
\hline$p_{\text {self }}$ & $\mathbf{s}$ & $\mathbf{h}$ & All benefits & Compensation & Competition & No benefit \\
\hline 0.4 & 0.5 & recessive & $0.1672(\mathrm{n}=5000)$ & $0.1617(\mathrm{n}=10000)$ & $0.0107(\mathrm{n}=10000)$ & $9 \mathrm{e}-04(\mathrm{n}=10000)$ \\
0.4 & 0.5 & additive & $0.0714(\mathrm{n}=5000)$ & $0.0718(\mathrm{n}=10000)$ & $0.0083(\mathrm{n}=10000)$ & $5 \mathrm{e}-04(\mathrm{n}=10000)$ \\
0.4 & 1 & uniform & $0.0542(\mathrm{n}=5000)$ & $0.0547(\mathrm{n}=10000)$ & $0.0066(\mathrm{n}=10000)$ & $0(\mathrm{n}=10000)$ \\
0.4 & 1 & recessive & $0.1468(\mathrm{n}=5000)$ & $0.149(\mathrm{n}=10000)$ & $5 \mathrm{e}-04(\mathrm{n}=10000)$ & $4 \mathrm{e}-04(\mathrm{n}=10000)$ \\
0.4 & 1 & additive & $0.0626(\mathrm{n}=5000)$ & $0.0532(\mathrm{n}=10000)$ & $0.0074(\mathrm{n}=10000)$ & $8 \mathrm{e}-04(\mathrm{n}=10000)$ \\
\hline 0.6 & uniform & uniform & $0.0576(\mathrm{n}=5000)$ & $0.0578(\mathrm{n}=10000)$ & $0.0043(\mathrm{n}=10000)$ & $7 \mathrm{e}-04(\mathrm{n}=10000)$ \\
0.6 & uniform & recessive & $0.0702(\mathrm{n}=5000)$ & $0.0672(\mathrm{n}=10000)$ & $0.0013(\mathrm{n}=10000)$ & $7 \mathrm{e}-04(\mathrm{n}=10000)$ \\
0.6 & uniform & additive & $0.0618(\mathrm{n}=5000)$ & $0.058(\mathrm{n}=10000)$ & $0.0057(\mathrm{n}=10000)$ & $5 \mathrm{e}-04(\mathrm{n}=10000)$ \\
0.6 & 0.1 & uniform & $0.0886(\mathrm{n}=5000)$ & $0.0917(\mathrm{n}=10000)$ & $0.0021(\mathrm{n}=10000)$ & $3 \mathrm{e}-04(\mathrm{n}=10000)$ \\
0.6 & 0.1 & recessive & $0.0938(\mathrm{n}=5000)$ & $0.1021(\mathrm{n}=10000)$ & $2 \mathrm{e}-04(\mathrm{n}=10000)$ & $5 e-04(\mathrm{n}=10000)$ \\
0.6 & 0.1 & additive & $0.0906(\mathrm{n}=5000)$ & $0.091(\mathrm{n}=10000)$ & $0.0036(\mathrm{n}=10000)$ & $2 \mathrm{e}-04(\mathrm{n}=10000)$ \\
0.6 & 0.5 & uniform & $0.0546(\mathrm{n}=5000)$ & $0.0512(\mathrm{n}=10000)$ & $0.006(\mathrm{n}=10000)$ & $7 \mathrm{e}-04(\mathrm{n}=10000)$ \\
0.6 & 0.5 & recessive & $0.0634(\mathrm{n}=5000)$ & $0.0607(\mathrm{n}=10000)$ & $0.0031(\mathrm{n}=10000)$ & $6 \mathrm{e}-04(\mathrm{n}=10000)$ \\
0.6 & 0.5 & additive & $0.0594(\mathrm{n}=5000)$ & $0.0557(\mathrm{n}=10000)$ & $0.006(\mathrm{n}=10000)$ & $2 \mathrm{e}-04(\mathrm{n}=10000)$ \\
0.6 & 1 & uniform & $0.0488(\mathrm{n}=5000)$ & $0.0399(\mathrm{n}=10000)$ & $0.0035(\mathrm{n}=10000)$ & $8 \mathrm{e}-04(\mathrm{n}=10000)$ \\
0.6 & 1 & recessive & $0.048(\mathrm{n}=5000)$ & $0.0417(\mathrm{n}=10000)$ & $4 \mathrm{e}-04(\mathrm{n}=10000)$ & $6 \mathrm{e}-04(\mathrm{n}=10000)$ \\
\hline
\end{tabular}




\begin{tabular}{|lllrrrr|}
\hline$p_{\text {self }}$ & $\mathbf{s}$ & $\mathbf{h}$ & All benefits & Compensation & Competition & No benefit \\
\hline 0.6 & 1 & additive & $0.0516(\mathrm{n}=5000)$ & $0.0445(\mathrm{n}=10000)$ & $0.0053(\mathrm{n}=10000)$ & $4 \mathrm{e}-04(\mathrm{n}=10000)$ \\
0.8 & uniform & uniform & $0.0374(\mathrm{n}=5000)$ & $0.0433(\mathrm{n}=10000)$ & $0.0035(\mathrm{n}=10000)$ & $4 \mathrm{e}-04(\mathrm{n}=10000)$ \\
0.8 & uniform & recessive & $0.042(\mathrm{n}=5000)$ & $0.0455(\mathrm{n}=10000)$ & $0.0023(\mathrm{n}=10000)$ & $2 \mathrm{e}-04(\mathrm{n}=10000)$ \\
0.8 & uniform & additive & $0.042(\mathrm{n}=5000)$ & $0.0416(\mathrm{n}=10000)$ & $0.0026(\mathrm{n}=10000)$ & $5 \mathrm{e}-04(\mathrm{n}=10000)$ \\
0.8 & 0.1 & uniform & $0.0658(\mathrm{n}=5000)$ & $0.0665(\mathrm{n}=10000)$ & $0.0022(\mathrm{n}=10000)$ & $5 \mathrm{e}-04(\mathrm{n}=10000)$ \\
0.8 & 0.1 & recessive & $0.0678(\mathrm{n}=5000)$ & $0.0747(\mathrm{n}=10000)$ & $7 \mathrm{e}-04(\mathrm{n}=10000)$ & $4 \mathrm{e}-04(\mathrm{n}=10000)$ \\
0.8 & 0.1 & additive & $0.066(\mathrm{n}=5000)$ & $0.066(\mathrm{n}=10000)$ & $0.0018(\mathrm{n}=10000)$ & $4 \mathrm{e}-04(\mathrm{n}=10000)$ \\
0.8 & 0.5 & uniform & $0.0386(\mathrm{n}=5000)$ & $0.0354(\mathrm{n}=10000)$ & $0.0042(\mathrm{n}=10000)$ & $0.0012(\mathrm{n}=10000)$ \\
0.8 & 0.5 & recessive & $0.0366(\mathrm{n}=5000)$ & $0.0323(\mathrm{n}=10000)$ & $0.0023(\mathrm{n}=10000)$ & $3 \mathrm{e}-04(\mathrm{n}=10000)$ \\
0.8 & 0.5 & additive & $0.0404(\mathrm{n}=5000)$ & $0.0375(\mathrm{n}=10000)$ & $0.0034(\mathrm{n}=10000)$ & $1 \mathrm{e}-04(\mathrm{n}=10000)$ \\
0.8 & 1 & uniform & $0.0308(\mathrm{n}=5000)$ & $0.0301(\mathrm{n}=10000)$ & $0.0032(\mathrm{n}=10000)$ & $3 \mathrm{e}-04(\mathrm{n}=10000)$ \\
0.8 & 1 & recessive & $0.033(\mathrm{n}=5000)$ & $0.0285(\mathrm{n}=10000)$ & $4 \mathrm{e}-04(\mathrm{n}=10000)$ & $5 \mathrm{e}-04(\mathrm{n}=10000)$ \\
0.8 & 1 & additive & $0.0388(\mathrm{n}=5000)$ & $0.0322(\mathrm{n}=10000)$ & $0.0041(\mathrm{n}=10000)$ & $2 \mathrm{e}-04(\mathrm{n}=10000)$ \\
\hline 1 & uniform & uniform & $0.0132(\mathrm{n}=5000)$ & $0.0138(\mathrm{n}=10000)$ & $0.0011(\mathrm{n}=10000)$ & $6 \mathrm{e}-04(\mathrm{n}=10000)$ \\
1 & uniform & recessive & $0.0102(\mathrm{n}=5000)$ & $0.0072(\mathrm{n}=10000)$ & $8 \mathrm{e}-04(\mathrm{n}=10000)$ & $2 \mathrm{e}-04(\mathrm{n}=10000)$ \\
1 & uniform & additive & $0.013(\mathrm{n}=5000)$ & $0.0127(\mathrm{n}=10000)$ & $0.0013(\mathrm{n}=10000)$ & $4 \mathrm{e}-04(\mathrm{n}=10000)$
\end{tabular}




\begin{tabular}{|lllrrrr|}
\hline$p_{\text {self }}$ & $\mathbf{s}$ & $\mathbf{h}$ & All benefits & Compensation & Competition & No benefit \\
\hline 1 & 0.1 & uniform & $0.0242(\mathrm{n}=5000)$ & $0.0223(\mathrm{n}=10000)$ & $4 \mathrm{e}-04(\mathrm{n}=10000)$ & $2 \mathrm{e}-04(\mathrm{n}=10000)$ \\
1 & 0.1 & recessive & $0.0214(\mathrm{n}=5000)$ & $0.0235(\mathrm{n}=10000)$ & $9 \mathrm{e}-04(\mathrm{n}=10000)$ & $8 \mathrm{e}-04(\mathrm{n}=10000)$ \\
1 & 0.1 & additive & $0.0196(\mathrm{n}=5000)$ & $0.0151(\mathrm{n}=10000)$ & $5 \mathrm{e}-04(\mathrm{n}=10000)$ & $3 \mathrm{e}-04(\mathrm{n}=10000)$ \\
1 & 0.5 & uniform & $0.0148(\mathrm{n}=5000)$ & $0.0154(\mathrm{n}=10000)$ & $0.0021(\mathrm{n}=10000)$ & $6 \mathrm{e}-04(\mathrm{n}=10000)$ \\
1 & 0.5 & recessive & $0.012(\mathrm{n}=5000)$ & $0.0084(\mathrm{n}=10000)$ & $0.0028(\mathrm{n}=10000)$ & $5 \mathrm{e}-04(\mathrm{n}=10000)$ \\
1 & 0.5 & additive & $0.0168(\mathrm{n}=5000)$ & $0.0161(\mathrm{n}=10000)$ & $0.0023(\mathrm{n}=10000)$ & $2 \mathrm{e}-04(\mathrm{n}=10000)$ \\
1 & 1 & uniform & $0.023(\mathrm{n}=5000)$ & $0.0228(\mathrm{n}=10000)$ & $0.0023(\mathrm{n}=10000)$ & $6 \mathrm{e}-04(\mathrm{n}=10000)$ \\
1 & 1 & recessive & $0.0268(\mathrm{n}=5000)$ & $0.0267(\mathrm{n}=10000)$ & $8 \mathrm{e}-04(\mathrm{n}=10000)$ & $6 \mathrm{e}-04(\mathrm{n}=10000)$ \\
1 & 1 & additive & $0.0246(\mathrm{n}=5000)$ & $0.025(\mathrm{n}=10000)$ & $0.0027(\mathrm{n}=10000)$ & $5 \mathrm{e}-04(\mathrm{n}=10000)$ \\
\hline
\end{tabular}


bioRxiv preprint doi: https://doi.org/10.1101/2020.11.17387340; this version posted November 17,2020 . The copyright holder for this preprint (which was not certified by peer review) is the author/funder, who has granted bioRxiv a license to display the preprint in perpetuity. It is made available under aCC-BY-NC-ND 4.0 International license.
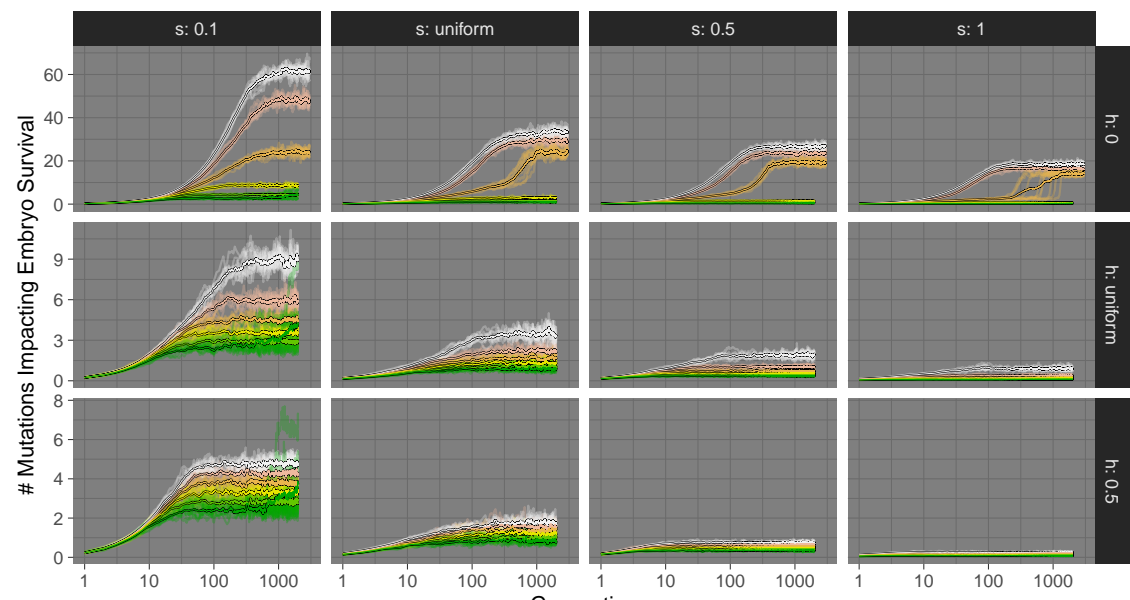

Selfing
Rate
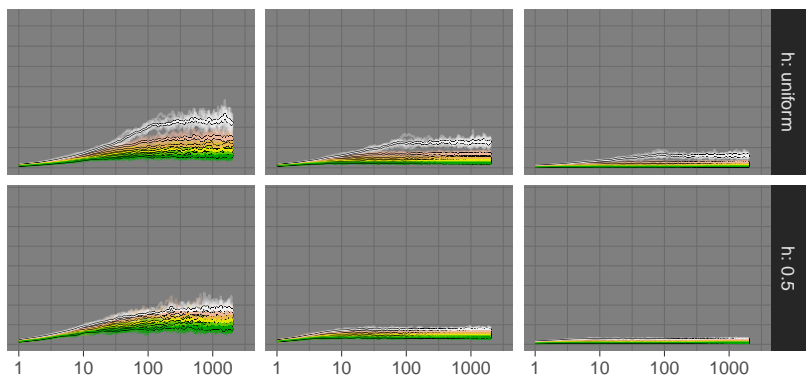

Generation

Figure S1: Overview of the life cycle model: The number of deleterious mutations impacting embryo fitness over time in burn in simulations, across selective $(s)$ and dominance $(h)$ coefficients, and selfing rates (on the $\mathrm{x}$-axis). 

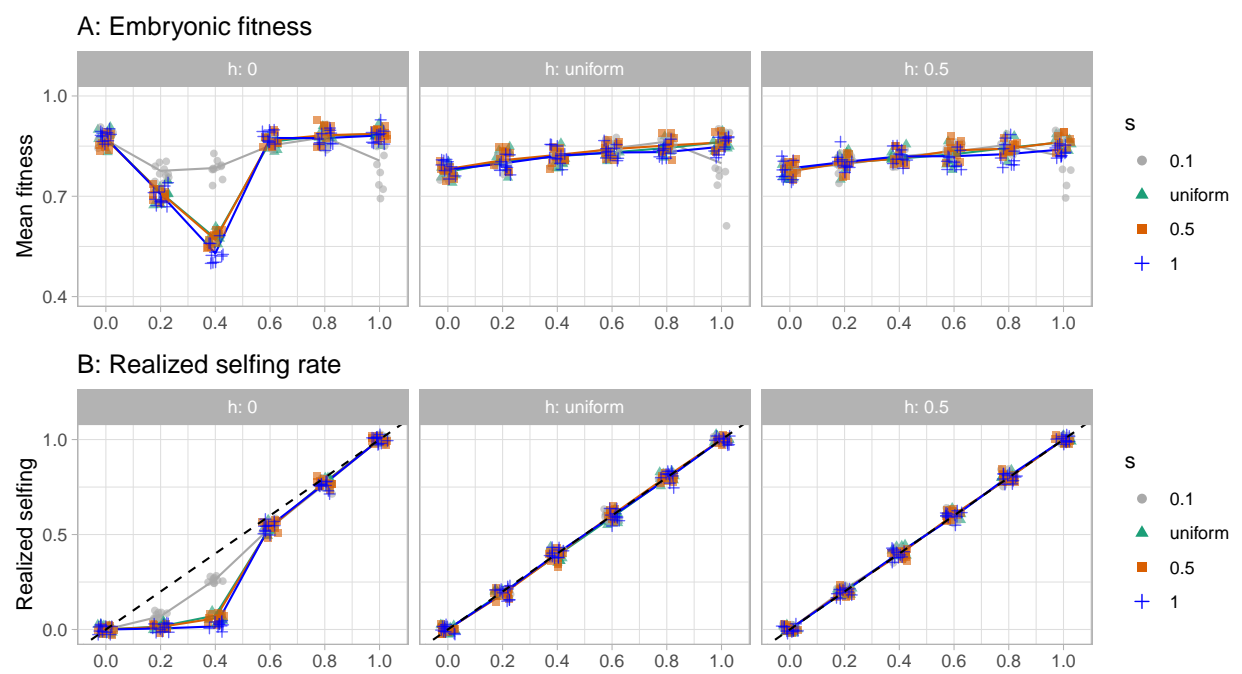

C: Correlation in pre- and post- embryo fitness
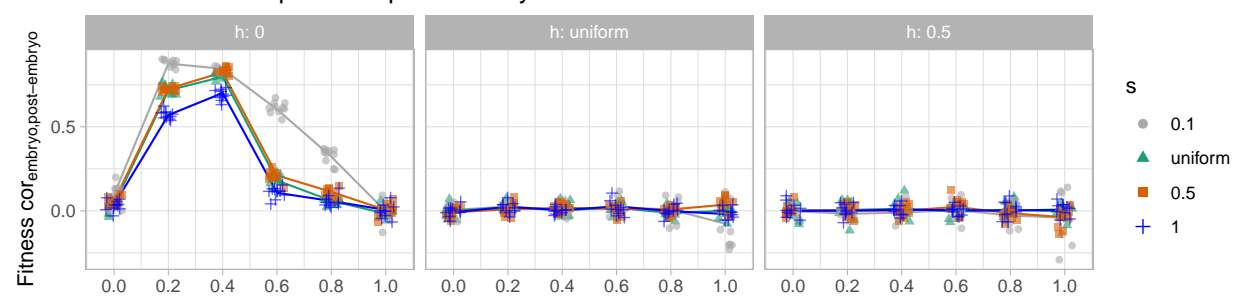

\section{D: Post-embryo fitness}

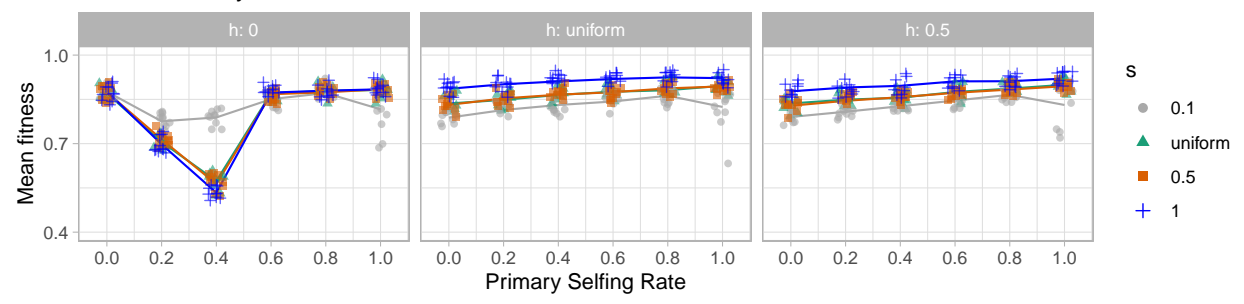

Figure S2: Summaries of our simulated populations at equilibrium: (A) The mean embryo fitness, (B) Realized selfing rate, (C) Correlation between embryo and postembryonic fitness, (D) Post-embryo fitness, across selective ( $s$, colors and shapes) and dominance ( $h$, facets) coefficients, and selfing rates (on the $\mathrm{x}$-axis). The number of deleterious mutations impacting embryo fitness over time in burn in simulations, across selective $(s)$ and dominance $(h)$ coefficients, and selfing rates (on the $\mathrm{x}$-axis). 


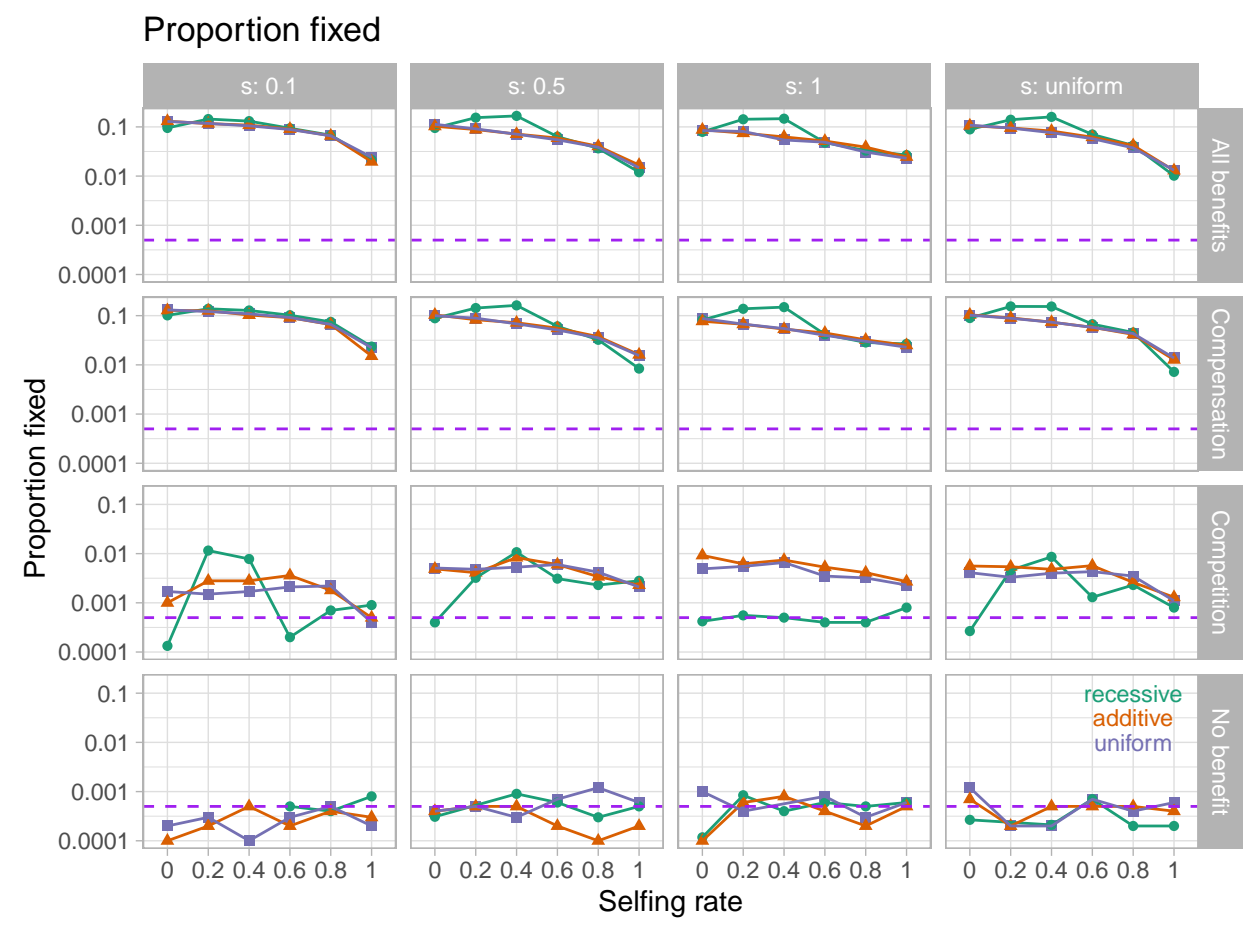

Figure S3: Proportion of introductions resulting in fixation as a function of selfing rate (x-axis), the benefit of polyembryony (rows), selection against new mutations (columns), and the dominance of new mutations (color). The purple line denotes neutral expectations. Note that fixation probabilities for additive mutations and those taking their value from a uniform distribution are very similar. 


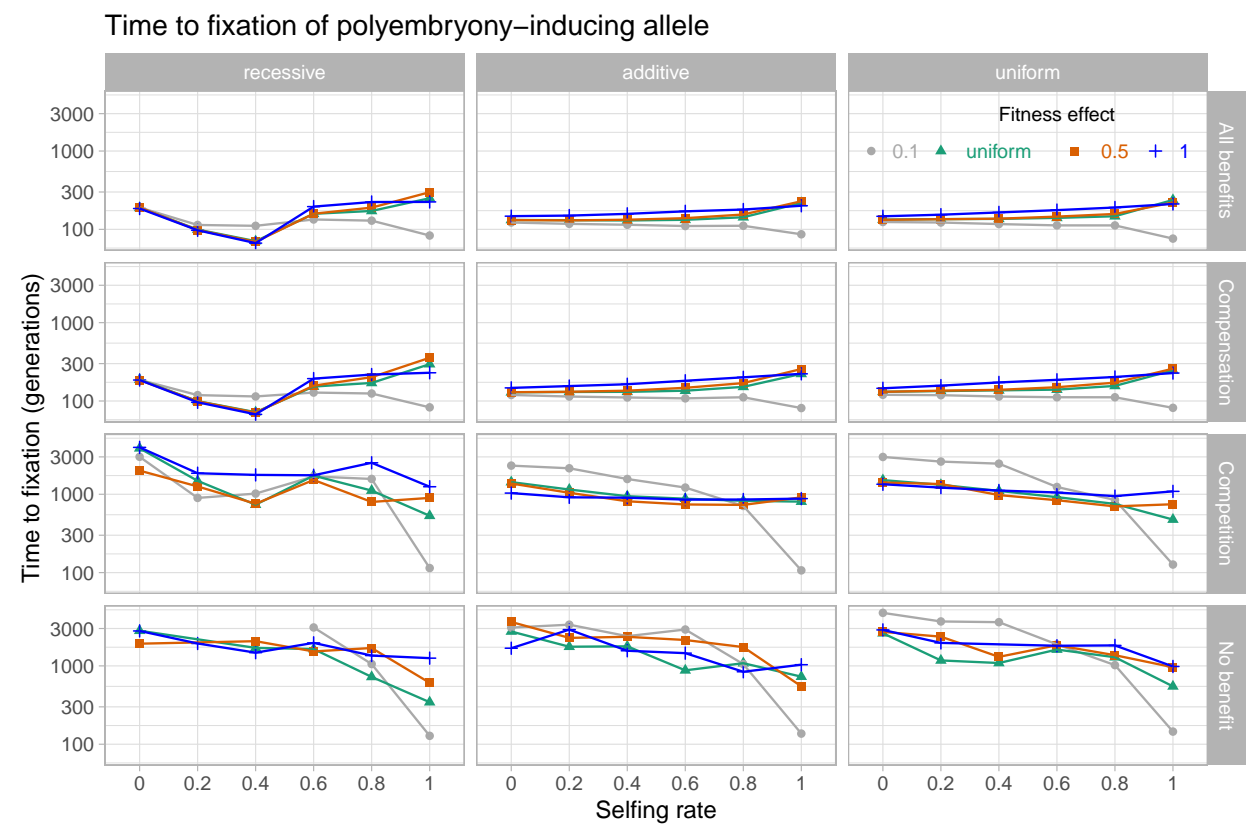

Figure S4: Mean time to fixation of the polyembryony allele across selective (s, colors and shapes) and dominance (h, faceted columns) coefficients, and selfing rates (on the x-axis), for each model (faceted rows).
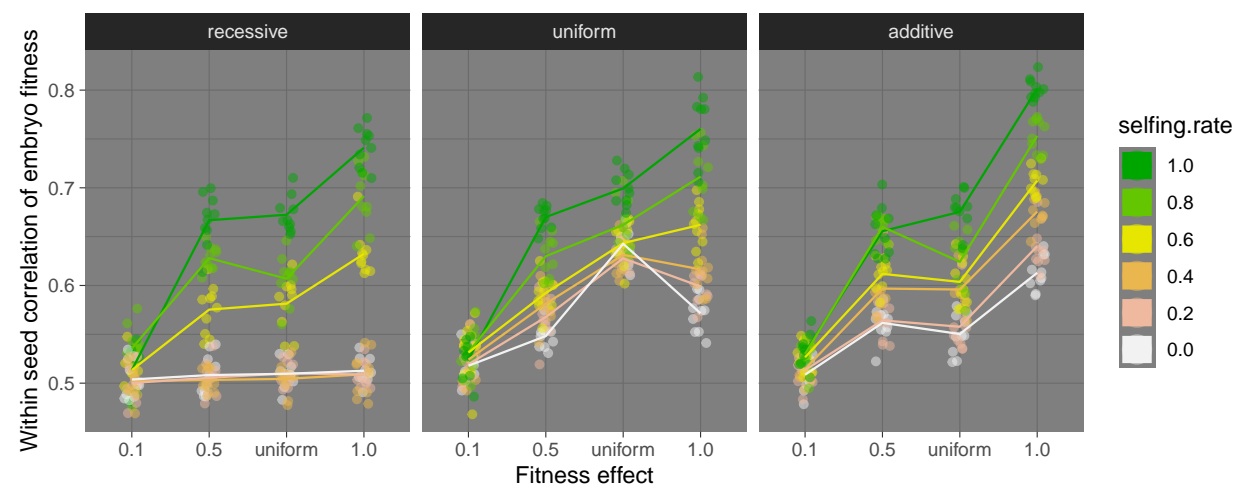

Figure S5: Correlation in fitness of the hypothetical two embryos in a seed, before polyembryony evolves as a function of the fitness effect of new mutations (on the x-axis), the selfing rate (color), and the dominance effect of new mutations (columns). 